\title{
A Theory of Collusion with Partial Mutual Understanding*
}

\author{
Joseph E. Harrington, Jr. ${ }^{\dagger}$
}

November 28, 2016

\begin{abstract}
Unlawful collusion is when firms have a mutual understanding to coordinate their behavior for the purpose of achieving a supracompetitive outcome. Given the legal focus on mutual beliefs, this paper explores the role of mutual beliefs in producing collusion. Focusing on price leadership, firms are assumed to commonly believe that price increases will be at least matched but lack any shared understanding about who will lead, when they will, and at what prices. Sufficient conditions are derived which ensure that supracompetitive prices emerge. However, price is bounded below the maximal equilibrium price.
\end{abstract}

*I am grateful for the comments of Emiliano Catonini, Peter Dijkstra, George Mailath, Phil Reny, and Nikos Vettas; seminar participants at Pompeu Fabra, Universitat de València, Penn-Wharton, U.S. Department of Justice, Toulouse School of Economics, U. of Rochester-Simon School, and the U. of Chicago; and conference participants at EARIE 2011, 2nd MaCCI Summer Institute in Competition Policy, and XXVII Jornadas de Economía Industrial. This research was partly conducted under a Cátedras de Excelencia at Carlos III de Madrid. I want to thank Banco Santander for funding and the faculty for providing a most collegial environment. This research has been conducted with the financial support of the National Science Foundation (SES-1148129).

${ }^{\dagger}$ Department of Business Economics \& Public Policy, The Wharton School, University of Pennsylvania, Philadelphia, PA 19107, harrij@wharton.upenn.edu 


\section{Introduction}

Collusion is when firms coordinate their behavior to suppress competition through such activities as raising prices, allocating markets, and bid rigging. In the U.S., unlawful collusion has come to mean that firms have an agreement to coordinate their behavior. In their interpretation of Section 1 of the Sherman Act, courts view an agreement as present when there is "mutual consent" among firms, ${ }^{1}$ when firms have "a conscious commitment to a common scheme designed to achieve an unlawful objective," 2 and when firms have a "unity of purpose or a common design and understanding, or a meeting of minds." 3 This perspective is not unique to the United States. Article 101 of the Treaty of the European Communities (1999) declares agreements to be unlawful that "have as their object or effect the prevention, restriction or distortion of competition" and the European Union General Court defines an agreement as when firms have "joint intention" (ACF Chemiefarma, 1970) and a "concurrence of wills" (Bayer v. Commission, 2000). In sum, firms unlawfully collude when there is mutual understanding to coordinate their behavior for the purpose of achieving a supracompetitive outcome. ${ }^{4}$

As a "meeting of minds" or "concurrence of wills" is not something that is directly observed, evidentiary standards for determining liability are based on communications that could produce mutual understanding and market behavior that is the possible consequence of mutual understanding. Some communication practices - such as firms expressly communicating a plan to coordinate prices or allocate markets - are subject to a per se prohibition. But then there are communication practices that are insufficient by themselves to establish liability but could deliver a guilty verdict when buttressed with corroborating market evidence that the communication was success-

\footnotetext{
${ }^{1}$ Esco Corp. v. United States, 340 F.2d 1000, 1007-08 (9th Cir. 1965).

${ }^{2}$ Monsanto Co. v. Spray-Rite Serv. Corp., 465 U.S. 752 (1984); 753.

${ }^{3}$ American Tobacco Co. v. United States, 328 U.S. 781 (1946); 810.

${ }^{4}$ For a critical examination of U.S. law with respect to price-fixing, the reader is referred to Kaplow (2013).
} 
ful in generating the requisite mutual understanding. For example, there are cases in which a single firm made an announcement that was public to all firms and thereby could serve to coordinate behavior. In Interstate Circuit, Inc. v. United States (1939), one firm sent a letter to each of the other firms that stated a plan to coordinate on price and made clear in the letter that every firm was receiving the same letter. In United States v. Foley (1980), there was a dinner among realtors during which one of them announced he was raising his commission rate from six to seven percent. In both of these cases, even though there was no exchange of assurances, firms were able to successfully coordinate their behavior.

The primary legal challenge is determining when firms share an understanding to raise prices, allocate markets, or engage in some other form of coordinated behavior. In defining the boundaries of unlawful collusion, this challenge can be broken down to addressing two questions. First, what is the relationship between communications among firms and the level of mutual understanding that is achieved? More specifically, what communication practices are effective in producing mutual beliefs among firms and with regards to what aspects of behavior is there mutual understanding? Second, what is the relationship between mutual understanding among firms and their market behavior? More specifically, what types of mutual beliefs result in coordination on prices and, more generally, supracompetitive outcomes?

The objective of this paper is to address the second question: How much and what type of mutual understanding results in collusive outcomes? On this question, the economic theory of collusion shows that if firms have mutual beliefs regarding a collusive strategy profile - that is, each firm has correct beliefs of this strategy profile - and incentive compatibility conditions hold (that is, the collusive strategy profile is an equilibrium) then supracompetitive outcomes will emerge. If firms were to communicate with each other using natural language in an unconstrained manner - as is done in hard core cartels (see Harrington 2006; Marshall and Marx, 2012) - it is reasonable to suppose that they could achieve mutual beliefs regarding the strategy 
profile. For example, managers could meet and express the intent to raise prices by $10 \%$ and to persist in doing so only if every firm charges $10 \%$ higher prices. If there are mutual beliefs regarding such a strategy and it is optimal for each firm to use that strategy, economic theory predicts supracompetitive outcomes will result. ${ }^{5}$

While it may be reasonable to expect firms, who have engaged in direct and unconstrained communication, to have mutual beliefs regarding the collusive strategy profile, there are many episodes of collusion for which communication was limited and, as a consequence, mutual understanding was likely to have been incomplete. Firms have attempted to coordinate their behavior through a wide variety of communication practices including tacking on a few digits to a multi-million dollar bid (FCC spectrum auctions; see Cramton and Schwartz, 2000), committing to a policy of non-negotiable posted prices (turbine generators; see Harrington, 2011), announcing future intended prices (airlines; see Borenstein, 2004), and unilaterally announcing a collusive pricing strategy (free-standing newspaper inserts; see In the Matter of Valassis Communications, Inc., Federal Trade Commission, File No. 051 0008, Docket No. C-4160, April 28, 2006). Presumably, the reason that firms chose such subtle forms of communication was because a more direct (and less discreet) method of communication would have enhanced the chances of detection, prosecution, and conviction. Thus, in an environment for which collusion is unlawful, firms will have an incentive to engage in indirect forms of communication which is then likely to limit the amount

\footnotetext{
${ }^{5}$ Equilibrium-based economic theory has also shed light on the first question though only when firms commonly know the strategy profile, and communication pertains to sharing information about firms' types (such as their costs) and the history (such as past sales). In Athey and Bagwell (2001, 2008), firms have private information about their cost and exchange (costless) messages, while in Hanazono and Yang (2007) and Gerlach (2009), firms have private signals on demand and seek to share that information. Then there is work in which sales or some other endogenous variable is private information and firms exchange messages for monitoring purposes; see Aoyagi (2002), Harrington and Skrzypacz (2011), Spector (2015), and Awaya and Krishna (2016). Finally, Chan and Zhang (2015) model the exchange of messages when both a firm's cost and sales are private information.
} 
of shared understanding. This then leads us back to our central research question: How much and what kind of mutual understanding is enough for firms to effectively collude?

Epistemic game theory provides a natural approach for addressing this question. Rather than specify a game and an equilibrium concept - which implicitly assumes firms have mutual beliefs with regards to a strategy profile - an epistemic approach begins with players' knowledge and beliefs about the game, players' rationality, and other players' beliefs. In its pure form, epistemic game theory places no prior structure on players' beliefs regarding other players' strategies and instead derives those beliefs; while equilibrium game theory assumes mutual beliefs with regards to a particular strategy profile and characterizes those strategy profiles consistent with rationality. The approach used here lies between these two extremes in that it assumes some prior mutual information on the strategies of other players - as might be achieved through limited forms of communication - but these mutual beliefs fall short of firms commonly knowing the entire strategy profile. ${ }^{6}$ The research program is to specify mutual beliefs regarding the game, firms' rationality, and firms' strategies and to then derive the implications for firm behavior with a particular focus on understanding when supracompetitive outcomes will emerge.

The setting is an infinitely repeated game with complete information and perfect monitoring but strategic uncertainty in that each firm is uncertain of other firms' strategies. A firm's strategy is required to be sequentially rational given its beliefs as to other firms' strategies where these beliefs are consistent with the prior mutual information regarding firms' strategies (referred to as first-order-belief restrictions) and the common belief that firms are sequentially rational. In executing this approach, we use strong-delta-rationalizability (Battigalli, 2003; Battigalli and Presipino, 2012) and characterize properties of price paths consistent with strong-delta-rationalizable

\footnotetext{
${ }^{6}$ Such a hybrid approach is also pursued in Catonini (2015a) which explores a related set of issues though in an abstract rather than an applied setting as here.
} 
strategies.

First-order-belief restrictions on strategies capture the prior common information that firms have about their strategies which is presumed to occur through some unmodelled communication. In this paper, the first-order-belief restriction is price leadership, which is one of the most common methods of collusion when firms do not engage in direct and unconstrained communication. ${ }^{7}$ Price leadership involves a firm raising price and other firms matching that price increase, with potentially multiple episodes of a firm leading and other firms following. It could have the same firm lead or firms could take turns. It could have many or few price increases; price increases could be large or small. The full strategy encompasses the timing of price increases, the size of price increases, and the identities of the firms leading the price increase. If firms do not engage in direct and unfettered communication, it is difficult to imagine that they could achieve mutual beliefs with respect to such details. Suppose instead firms only have mutual beliefs that price increases will be at least matched by the other firms, and failure to do so means a return to competitive prices. This level of mutual understanding could possibly be achieved through public announcements such as firms announcing that they will not undercut rival firms' prices. In that case, a firm conveys its intent to avoid aggressive competition but its announcement falls far short of expressing a plan to coordinate prices. For example, U-Haul CEO Joe Schoen conveyed during an earnings conference call with analysts that it thought rival Budget's price undercutting in the truck rental market was nonsensical and proposed moving to price leadership. ${ }^{8}$ While such an announcement did not meet the evidentiary standards for Section 1 of the Sherman Act, the Federal Trade Commission pursued a Section 5 case (under the Federal Trade Commission Act) against U-Haul as an "invitation to collude". ${ }^{9}$

\footnotetext{
${ }^{7}$ For some examples, see Markham (1951) and Scherer (1980, Chapter 6).

${ }^{8}$ Matter of U-Haul Int'l Inc. and AMERCO (FTC File No. 081-0157, July 10, 2010)

${ }^{9}$ Even when it might be clear as to which firm will make the initial price increase, there could still be uncertainty as to who will initiate future price increases. Given that taking the lead is costly
} 
It is assumed here that the game and firms' rationality are common knowledge and that there is common knowledge regarding the following properties of firms' strategies: price increases will be at least matched and failure to do so results in noncollusive (static Nash equilibrium) prices. Two questions are addressed. First, are these mutual beliefs sufficient to result in supracompetitive prices? Second, if they can achieve supracompetitive prices, are those prices less than what would be achieved if there was mutual understanding of the entire strategy profile (that is, equilibrium)? To my knowledge, this is the first paper to investigate when less than full mutual understanding of a collusive strategy profile is sufficient to generate effective collusion.

There are two main results. The first finding is that if it is common knowledge that price increases will be at least matched (and failure to do so will result in competitive prices) then an upper bound on price is derived that is strictly less than the maximal price achieved under equilibrium (using the same implicit punishment). Thus, in this particular setting, less than full mutual understanding of the strategy profile does limit the extent of collusion. The reason is that without mutual beliefs regarding the collusive price, coordinating on a higher collusive price requires some firm to take the lead in raising price and this is a costly enterprise which limits the extent of price increases. While an upper bound on price is derived, no more can be said about price paths induced by this set of mutual beliefs; it could involve competitive or supracompetitive prices. Thus, in answer to the first question, mutual beliefs that price increases will be at least matched does not imply supracompetitive prices.

With only mutual beliefs that price increases will be at least matched, a firm can assign positive probability to many strategies for the other firms. For example, a firm could believe that another firm will always act as a price leader or instead that other

- as a firm raises its price before others do - each firm would like another firm to lead which could generate miscoordination. Consistent with this view, equilibrium analyses show that "a leaderfollower pattern where a single firm consistently leads all price changes is unlikely" (Pastine and Pastine, 2004, p. 136) and there is delay in price leadership because each firm waits for the other to take the lead (Harrington and Zhao, 2012). 
firms believe it'll be the price leader. I then make some plausible assumptions on firms' prior beliefs and apply a result of Kalai and Lehrer (1993) to show that firms eventually succeed in coordinating on supracompetitive prices. Thus, supracompetitive prices are sure to emerge even though firms lack common knowledge about who will lead on price, when they will lead, and what prices they will charge. That is the second main finding of the paper.

The model is described in Section 2 - where standard assumptions are made regarding cost, demand, and firm objectives - and in Section 3 - where, consistent with the epistemic approach, assumptions are made regarding the behavior and beliefs of firms. An upper bound on price is characterized in Section 4. The implications of additional structure on how firms learn about other firms' strategies is explored in Section 5. Section 6 offers a few concluding remarks. Proofs are in the appendices.

\section{Assumptions on the Market}

Consider a symmetric differentiated products price game with $n \geq 2$ firms. $\pi\left(p_{i}, \mathbf{p}_{-i}\right)$ : $\Re_{+}^{n} \rightarrow \Re$ is a firm $i$ 's profit when it prices at $p_{i}$ and its rivals price at $\mathbf{p}_{-i} \equiv$ $\left(p_{1}, \ldots, p_{i-1}, p_{i+1}, \ldots, p_{n}\right)$. Assume $\pi\left(p_{i}, \mathbf{p}_{-i}\right)$ is bounded, twice continuously differentiable, increasing in a rival's price $p_{j}(j \neq i)$, and strictly concave in own price $p_{i}$. A firm's best reply function then exists: $\psi\left(\mathbf{p}_{-i}\right)=\arg \max _{p_{i}} \pi\left(p_{i}, \mathbf{p}_{-i}\right)$. Further assume $\partial^{2} \pi / \partial p_{i} \partial p_{j}>0, \forall j \neq i$ from which it follows that $\psi\left(\mathbf{p}_{-i}\right)$ is increasing in $p_{j}$, $j \neq i$. A symmetric Nash equilibrium price, $p^{N}$, exists and is assumed to be unique, $\psi(p, . ., p) \gtreqless p$ as $p \lesseqgtr p^{N}$, and let $\pi^{N} \equiv \pi\left(p^{N}, \ldots, p^{N}\right)>0$.

Assuming $\pi(p, \ldots, p)$ is strictly concave in $p$, there exists a unique joint profit $\operatorname{maximum} p^{M}$,

$$
\sum_{j=1}^{n} \frac{\partial \pi(p, \ldots, p)}{\partial p_{j}} \gtreqless 0 \text { as } p \lesseqgtr p^{M}
$$

and $p^{M}>p^{N}$.

Firms interact in an infinitely repeated price game with perfect monitoring. A 
collusive price $p^{\prime}>p^{N}$ is sustainable with the grim trigger strategy if and only if: ${ }^{10}$

$$
\left(\frac{1}{1-\delta}\right) \pi\left(p^{\prime}, \ldots, p^{\prime}\right) \geq \max _{p_{i}} \pi\left(p_{i}, p^{\prime}, \ldots, p^{\prime}\right)+\left(\frac{\delta}{1-\delta}\right) \pi^{N}
$$

where $\delta$ is the common discount factor. Define $\widetilde{p}$ as the best price sustainable using the grim trigger strategy:

$$
\widetilde{p} \equiv \max \left\{p \in\left[p^{N}, p^{M}\right]:\left(\frac{1}{1-\delta}\right) \pi(p, \ldots, p) \geq \max _{p_{i}<p} \pi\left(p_{i}, p, \ldots, p\right)+\left(\frac{\delta}{1-\delta}\right) \pi^{N}\right\} .
$$

Assume $\widetilde{p}>p^{N}$ and if $\widetilde{p} \in\left(p^{N}, p^{M}\right)$ then

$$
\left(\frac{1}{1-\delta}\right) \pi(p, \ldots, p) \gtreqless \pi(\psi(p, \ldots, p), p, \ldots, p)+\left(\frac{\delta}{1-\delta}\right) \pi^{N} \text { as } p \lesseqgtr \widetilde{p} \text { for } p \in\left[p^{N}, p^{M}\right] \text {. }
$$

$\widetilde{p}$ will prove to be a useful benchmark.

For the later analysis, consider the "price matching" objective function for a firm:

$$
W\left(p_{i}, \mathbf{p}_{-i}\right) \equiv \pi\left(p_{i}, \mathbf{p}_{-i}\right)+\left(\frac{\delta}{1-\delta}\right) \pi\left(p_{i}, \ldots, p_{i}\right)
$$

Given its rivals price at $\mathbf{p}_{-i}$ in the current period, $W\left(p_{i}, \mathbf{p}_{-i}\right)$ is firm $i$ 's payoff from pricing at $p_{i}$ if it believed that all firms would match that price in all ensuing periods. Consider

$$
\frac{\partial W\left(p_{i}, \mathbf{p}_{-i}\right)}{\partial p_{i}}=\frac{\partial \pi\left(p_{i}, \mathbf{p}_{-i}\right)}{\partial p_{i}}+\left(\frac{\delta}{1-\delta}\right) \sum_{j=1}^{n} \frac{\partial \pi\left(p_{i}, \ldots, p_{i}\right)}{\partial p_{j}}
$$

If $p_{i}<p^{M}$ then the second term is positive; by raising its current price, a firm increases the future profit stream under the assumption that its price increase will be matched by its rivals. If $p_{i}>\psi\left(p_{-i}\right)$ then the first term is negative. Evaluate $\frac{\partial W\left(p_{i}, p_{-i}\right)}{\partial p_{i}}$ when firms price at a common level $p$ :

$$
\frac{\partial W(p, \ldots, p)}{\partial p_{i}}=\left(\frac{1}{1-\delta}\right)\left(\frac{\partial \pi(p, \ldots, p)}{\partial p_{i}}+\delta \sum_{j \neq i}^{n} \frac{\partial \pi(p, \ldots, p)}{\partial p_{j}}\right)
$$

Thus, when $p \in\left(p^{N}, p^{M}\right)$, raising price lowers current profit, $\frac{\partial \pi(p, \ldots, p)}{\partial p_{i}}<0$, and increases future profit, $\sum_{j=1}^{n} \frac{\partial \pi(p, \ldots, p)}{\partial p_{j}}>0$. By the preceding assumptions, $W\left(p_{i}, \mathbf{p}_{-i}\right)$

\footnotetext{
${ }^{10}$ The grim trigger strategy has any deviation from the collusive price $p^{\prime}$ result in a price of $p^{N}$ forever.
} 
is strictly concave in $p_{i}$ since it is the weighted sum of two strictly concave functions. Hence, a unique optimal price exists,

$$
\phi\left(\mathbf{p}_{-i}\right)=\arg \max _{p_{i}} W\left(p_{i}, \mathbf{p}_{-i}\right)
$$

By the preceding assumptions, $\phi\left(\mathbf{p}_{-i}\right)$ is increasing in a rival's price as

$$
\frac{\partial \phi\left(\mathbf{p}_{-i}\right)}{\partial p_{j}}=-\frac{\partial^{2} W\left(p_{i}, \mathbf{p}_{-i}\right) / \partial p_{i} \partial p_{j}}{\partial^{2} W\left(p_{i}, \mathbf{p}_{-i}\right) / \partial p_{i}^{2}}=-\frac{\frac{\partial^{2} \pi\left(p_{i}, \mathbf{p}_{-i}\right)}{\partial p_{i} \partial p_{j}}}{\frac{\partial^{2} \pi\left(p_{i}, \mathbf{p}_{-i}\right)}{\partial p_{i}^{2}}+\left(\frac{\delta}{1-\delta}\right)\left(\frac{\partial^{2} \pi(p, \ldots, p)}{\partial p^{2}}\right)}>0
$$

As there is a benefit in terms of future profit from raising price (as long as it does not exceed the joint profit maximum) then the price matching best reply function results in a higher price than the standard best reply function. To show this result, consider

$$
\begin{aligned}
\frac{\partial W\left(\psi\left(\mathbf{p}_{-i}\right), \mathbf{p}_{-i}\right)}{\partial p_{i}} & =\frac{\partial \pi\left(\psi\left(\mathbf{p}_{-i}\right), \mathbf{p}_{-i}\right)}{\partial p_{i}}+\left(\frac{\delta}{1-\delta}\right) \sum_{j=1}^{n} \frac{\partial \pi\left(\psi\left(\mathbf{p}_{-i}\right), \ldots, \psi\left(\mathbf{p}_{-i}\right)\right)}{\partial p_{j}} \\
& =\left(\frac{\delta}{1-\delta}\right) \sum_{j=1}^{n} \frac{\partial \pi\left(\psi\left(\mathbf{p}_{-i}\right), \ldots, \psi\left(\mathbf{p}_{-i}\right)\right)}{\partial p_{j}}>0
\end{aligned}
$$

which is positive because $\mathbf{p}_{-i} \leq\left(p^{M}, \ldots, p^{M}\right)$ implies $\psi\left(\mathbf{p}_{-i}\right)<p^{M}{ }^{11}$ By the strict concavity of $W, \phi\left(\mathbf{p}_{-i}\right)>\psi\left(\mathbf{p}_{-i}\right)$.

$\phi$ has a fixed point $p^{*}$ because it is continuous, $\phi\left(p^{N}, \ldots, p^{N}\right)>p^{N}$, and

$$
\frac{\partial W\left(p^{M}, \ldots, p^{M}\right)}{\partial p_{i}}=\frac{\partial \pi\left(p^{M}, \ldots, p^{M}\right)}{\partial p_{i}}<0 \Rightarrow \phi\left(p^{M}, \ldots, p^{M}\right)<p^{M} .
$$

Further assume the fixed point is unique: $\phi(p, \ldots, p) \gtreqless p$ as $p \lesseqgtr p^{*}$. Thus, if rival firms price at $p^{*}$, a firm prefers to price at $p^{*}$ rather than price differently under the assumption that its price will be matched forever. $p^{*}$ will prove to be a useful benchmark.

The price set is assumed to be finite. From hereon, assume the price set is $\Omega \equiv$ $\{0, \varepsilon, 2 \varepsilon, \ldots, P\}$, where $P$ is some upper bound on price and $\varepsilon>0$ and is presumed

\footnotetext{
${ }^{11}$ Since $\psi(p, . ., p) \gtreqless p$ as $p \lesseqgtr p^{N}$ then $\psi\left(p^{M}, . ., p^{M}\right)<p^{M}$. Given that $\psi$ is increasing then $\mathbf{p}_{-i} \leq\left(p^{M}, \ldots, p^{M}\right)$ implies $\psi\left(\mathbf{p}_{-i}\right)<\psi\left(p^{M}, . ., p^{M}\right)<p^{M}$.
} 
to be small. For convenience, suppose $p^{N}, p^{*}, \widetilde{p} \in \Omega{ }^{12}$ As the finiteness of the price set could generate multiple optima, define the best reply correspondence for the price matching objective function:

$$
\bar{\phi}\left(\mathbf{p}_{-i}\right) \equiv \arg \max _{p_{i} \in \Omega} \pi\left(p_{i}, \mathbf{p}_{-i}\right)+\left(\frac{\delta}{1-\delta}\right) \pi\left(p_{i}, \ldots, p_{i}\right)
$$

The best reply correspondence is assumed to have the following property: ${ }^{13}$

$$
\bar{\phi}\left(\mathbf{p}_{-i}\right) \begin{cases}\subseteq\left\{p^{\prime}+\varepsilon, \ldots, p^{*}\right\} & \text { if } \mathbf{p}_{-i}=\left(p^{\prime}, \ldots, p^{\prime}\right) \text { where } p^{\prime}<p^{*}-\varepsilon \\ =\left\{p^{*}\right\} & \text { if } \mathbf{p}_{-i}=\left(p^{*}, \ldots, p^{*}\right) \\ \subseteq\left\{p^{*}, \ldots, p^{\prime}-\varepsilon\right\} & \text { if } \mathbf{p}_{-i}=\left(p^{\prime}, \ldots, p^{\prime}\right) \text { where } p^{\prime}>p^{*}+\varepsilon\end{cases}
$$

Recall that $p^{*}$ is the unique fixed point for $\phi\left(\mathbf{p}_{-i}\right)$; it is also a fixed point for $\bar{\phi}\left(\mathbf{p}_{-i}\right)$. By (4), if all rival firms price at $p^{\prime}$ then firm $i$ 's best reply has it price above $p^{\prime}$ when $p^{\prime}<p^{*}-\varepsilon$. Analogously, if $p^{\prime}>p^{*}+\varepsilon$ then firm $i$ 's best reply has it price below $p^{\prime}$. Note that an implication of (4) is that the set of symmetric fixed points of $\bar{\phi}\left(\mathbf{p}_{-i}\right)$ is, at most, $\left\{p^{*}-\varepsilon, p^{*}, p^{*}+\varepsilon\right\} .^{14}$

\section{Assumptions on Beliefs and Behavior}

Let us now turn to specifying firms' mutual beliefs regarding rationality and strategies. For this purpose, I define the following terms. $\mathcal{H} \equiv\{\varnothing\} \cup\left(\cup_{t \geq 1} \Omega^{n \times t}\right)$ is the space of histories for the infinitely repeated price game with perfect monitoring. $s_{i}: \mathcal{H} \rightarrow \Omega$ is a strategy for firm $i$ and $S$ denotes a firm's strategy set, which is common to all firms. $\mu^{i}\left(s_{-i} \mid h\right): \mathcal{H} \rightarrow \Delta\left(S^{n-1}\right)$ is firm $i$ 's beliefs on the strategies of the other firms conditional on the history $h \in \mathcal{H}$ where $\Delta(X)$ is the set of probability distributions on set $X^{15}$

\footnotetext{
${ }^{12}$ If $\widetilde{p} \in \Omega$ and $\psi(\widetilde{p}, \ldots, \widetilde{p}) \in \Omega$ then $\widetilde{p}$ is still the best price sustainable using the grim punishment.

${ }^{13} \mathrm{~A}$ sufficient condition for $(4)$ is $-\partial^{2} \pi / \partial p_{i}^{2} \geq 2\left(\partial^{2} \pi / \partial p_{i} \partial p_{-i}\right)$.

${ }^{14}$ The case of linear demand and cost functions satisfies all of the assumptions made in Section 2.

${ }^{15}$ Standard assumptions on $\mu^{i}$ are presumed, as stated in Definition 2.2 in Battigalli (2003).
} 
Starting from the current period based on history $h$, let $U_{i}\left(s_{i}, \mu^{i}(\cdot \mid h)\right)$ be the expected present value of profits for firm $i$ after history $h$ given firm $i$ 's strategy is $s_{i}$ and firm $i$ 's beliefs on the other firms' strategies are $\mu^{i}(\cdot \mid h)$. Given beliefs as to other firms' strategies, a firm's strategy is sequentially rational if it is optimal for all histories.

Definition: $\widehat{s}_{i}$ is sequentially rational with respect to beliefs $\mu^{i}$ if, $\forall h \in \mathcal{H}, U_{i}\left(\widehat{s}_{i}, \mu^{i}(\cdot \mid h)\right) \geq$ $U_{i}\left(s_{i}, \mu^{i}(\cdot \mid h)\right) \forall s_{i} \in S$.

$\rho_{i}\left(\mu^{i}\right)$ denotes the set of sequentially rational strategies given beliefs $\mu^{i}$ and $\rho_{i}\left(\Delta^{i}\right) \equiv$ $\cup_{\mu^{i} \in \Delta^{i}} \rho_{i}\left(\mu^{i}\right)$.

Critical to our approach is allowing firms to have a reasonable amount of mutual understanding with respect to the strategy profile. As is laid out in the ensuing assumptions, the presumption is that firms believe that a higher price (up to some maximum level) will be at least matched and that any deviation - such as undercutting a rival firm's price - will result in a return to competitive pricing. This description of behavior is more formally stated as the price matching plus (PMP) property.

Definition: The strategy of firm $i$ has the price matching plus (PMP) property if, for some $\bar{p}$,

$$
\begin{array}{ll}
p_{i}^{t}\left\{\left\{\max \left\{p_{1}^{t-1}, \ldots, p_{n}^{t-1}\right\}, \ldots, \bar{p}\right\} \quad\right. & \text { if } p_{j}^{\tau} \geq \min \left\{\max \left\{p_{1}^{\tau-1}, \ldots, p_{n}^{\tau-1}\right\}, \bar{p}\right\} \forall j, \forall \tau \leq t-1 \\
& \text { and } \max \left\{p_{1}^{t-1}, \ldots, p_{n}^{t-1}\right\}<\bar{p} \\
& \\
& \text { if } p_{j}^{\tau} \geq \min \left\{\max \left\{p_{1}^{\tau-1}, \ldots, p_{n}^{\tau-1}\right\}, \bar{p}\right\} \forall j, \forall \tau \leq t-1 \\
& \text { and } \max \left\{p_{1}^{t-1}, \ldots, p_{n}^{t-1}\right\} \geq \bar{p} \\
& \\
& \text { if } \operatorname{not} p_{j}^{\tau} \geq \min \left\{\max \left\{p_{1}^{\tau-1}, \ldots, p_{n}^{\tau-1}\right\}, \bar{p}\right\} \\
& \forall j, \forall \tau \leq t-1
\end{array}
$$

First note that matching a price increase means setting $p_{i}^{t}=\max \left\{p_{1}^{t-1}, \ldots, p_{n}^{t-1}\right\}$. Thus, as of period $t$, price increases have always been at least matched when $p_{j}^{\tau} \geq$ 
$\max \left\{p_{1}^{\tau-1}, \ldots, p_{n}^{\tau-1}\right\} \forall j, \forall \tau \leq t-1$. Price matching plus behavior is subject to the caveat that firms are only expected to match price as high as $\bar{p}$; thus, firms are not expected to follow an excessively high price increase. Firms have then been complying with this modified price matching when $p_{j}^{\tau} \geq \min \left\{\max \left\{p_{1}^{\tau-1}, \ldots, p_{n}^{\tau-1}\right\}, \bar{p}\right\} \forall j, \forall \tau \leq$ $t-1$. In that event, the PMP property has a firm price in period $t$ at least as high as $\max \left\{p_{1}^{t-1}, \ldots, p_{n}^{t-1}\right\}$ with the caveat of not pricing in excess of $\bar{p}$. Finally, if any firm should fail to act in a manner consistent with the previously described behavior then firms revert to pricing at the non-collusive price $p^{N}$ thereafter. ${ }^{16}$

A strategy satisfying the PMP property is referred to as PMP-compatible and $S^{P M P}$ will denote the set of PMP-compatible strategies. Define $S^{P M P}(h)$ as the set of strategies that satisfy the PMP property starting with history $h$; that is, a strategy is an element of $S^{P M P}(h)$ if its projection on the game defined by history $h$ satisfies the PMP property. The key first-order-belief restriction is that there is mutual understanding among firms that their behavior is consistent with the PMP property or, as defined below, their beliefs are PMP-consistent.

Definition: $\mu^{i}$ is PMP-consistent if $\mu^{i}: \mathcal{H} \rightarrow \Delta\left(\left(S^{P M P}(h)\right)^{n-1}\right), \forall h \in \mathcal{H}$.

$\triangle^{P M P}$ is defined to be the set of PMP-consistent beliefs. ${ }^{17}$

In defining what we mean by mutual understanding, we use the concept of mutual strong beliefs from Battigalli (2003) and Battigalli and Siniscalchi (2003). A firm has strong beliefs regarding some event if it is certain about that event and that certainty is maintained as long as the history is consistent with it.

\footnotetext{
${ }^{16}$ The potential role of price matching here is to coordinate on a collusive outcome. Price matching has also been explored as a form of punishment; see Lu and Wright (2010) and Garrod (2012). Some papers exploring price leadership as a collusive equilibrium include Rotemberg and Saloner (1990) and Mouraviev and Rey (2011).

${ }^{17}$ By this definition, if past play is inconsistent with firms using PMP-compatible strategies then - by continuing to believe play is described by the PMP property - a firm expects other firms to price at $p^{N}$ thereafter.
} 
Definition: A firm strongly believes event $\mathrm{E}$ if it is initially certain of $\mathrm{E}$ and would also be certain of $\mathrm{E}$ conditional on every history whose occurrence does not contradict E.

Definition: Firms have a mutual strong belief in E if each firm strongly believes E.

As described as A1, the behavioral assumption is that firms are sequentially rational, and the belief assumption is that there is an infinite hierarchy of mutual strong beliefs that firms are sequentially rational and use strategies that have the PMP property. Note that it is not assumed that firms use a PMP-compatible strategy; that will be an implication of sequential rationality and these beliefs.

Assumption A1: Assume $\cap_{q \geq 0} \mathcal{A}^{q}$ where

$\mathcal{A}^{0}$ : Every firm is sequentially rational and has beliefs that are PMP-consistent. $\mathcal{A}^{1}$ : There is mutual strong belief in $\mathcal{A}^{0}$.

$\mathcal{A}^{2}$ : There is mutual strong belief in $\mathcal{A}^{0} \cap \mathcal{A}^{1}$.

$\vdots$

$\mathcal{A}^{m+1}$ : There is mutual strong belief in $\mathcal{A}^{0} \cap \cdots \cap \mathcal{A}^{m}$.

Strategies and beliefs that satisfy A1 are strong-delta-rationalizable with the first-order-belief restrictions that each firm believes other firms use PMP-compatible strategies. ${ }^{18}$ Using the definition in Battigalli (2003), a more formal statement of A1 is as follows. Define $S_{i}(h)$ as the set of strategies for firm $i$ that are consistent with history $h$ and $S_{-i}(h)$ as the set of strategies for all firms but $i$ that are consistent with

\footnotetext{
${ }^{18} \mathrm{An}$ alternative approach would be to use the concept of strongly rationalizable strategies (Catonini, 2015b). These approaches differ in how beliefs respond to events inconsistent with a player's prior beliefs and whether priority is given to rationality or to first-order-belief restrictions.
} 
history $h$. Defining $\Sigma_{i}\left(0, \Delta^{P M P}\right)=S_{i}$ and $\Phi^{i}\left(0, \Delta^{P M P}\right)=\Delta^{P M P}, \Sigma_{i}\left(k, \Delta^{P M P}\right)$ and $\Phi^{i}\left(k, \Delta^{P M P}\right)$ are defined recursively for $k=0,1, \ldots$ :

$$
\begin{aligned}
\Phi^{i}\left(k+1, \Delta^{P M P}\right)= & \left\{\mu^{i} \in \Phi^{i}\left(k, \Delta^{P M P}\right): \forall h \in \mathcal{H}, S_{-i}(h) \cap \Sigma_{-i}\left(k, \Delta^{P M P}\right) \neq \varnothing\right. \\
\Rightarrow & \left.\mu^{i}\left(\Sigma_{-i}\left(k, \Delta^{P M P}\right) \mid h\right)=1\right\} \\
& \Sigma_{i}\left(k+1, \Delta^{P M P}\right)=\rho_{i}\left(\Phi^{i}\left(k, \Delta^{P M P}\right)\right)
\end{aligned}
$$

The set of strong-delta-rationalizable strategies is $\Sigma_{i}\left(\infty, \Delta^{P M P}\right)$. To explain this definition, first note that $\Sigma_{i}\left(1, \Delta^{P M P}\right)=\rho_{i}\left(\Delta^{P M P}\right)$ so a strategy is an element of $\Sigma_{i}\left(1, \Delta^{P M P}\right)$ if there are beliefs in $\Delta^{P M P}$ such that the strategy is sequentially rational. Beliefs are an element of $\Phi^{i}\left(1, \Delta^{P M P}\right)$ if they put unit mass on other firms using PMP-compatible strategies when the history is consistent with other firms using PMP-compatible strategies:

$$
\Phi^{i}\left(1, \Delta^{P M P}\right)=\left\{\mu^{i} \in \Delta^{P M P}: \forall h \in \mathcal{H}, S_{-i}(h) \cap S_{-i} \neq \varnothing \Rightarrow \mu^{i}\left(S_{-i} \mid S_{-i}(h)\right)=1\right\}
$$

A strategy is an element of $\Sigma_{i}\left(2, \Delta^{P M P}\right)$ if it is sequentially rational for some beliefs in $\Phi^{i}\left(1, \Delta^{P M P}\right)$ which means firm $i$ believes firm $j, \forall j \neq i$, uses a PMP-compatible strategy which is itself sequentially rational for some beliefs on firm $k$ using a PMPcompatible strategy, $\forall k \neq j$. Higher levels are analogously defined.

An implication of A1 is that there is common knowledge among firms that: 1) price increases are at least matched as long as past price increases have been at least matched in the past; 2) price increases will be followed only as high as $\bar{p}$; and 3) departure from this price matching behavior results in reversion to non-collusive pricing. Let me discuss each these features.

Consider the assumption that it is common knowledge that failure to at least match price increases (up to a maximum price of $\bar{p}$ ) results in non-collusive pricing thereafter. It is useful to break this assumption into two parts: 1) a departure from price matching results in some form of punishment; and 2) that punishment is the grim punishment. The second condition is unimportant because results are 
unchanged if the punishment is at least as severe as the grim punishment. The first condition seems natural in that firms are seeking to collude through the mutual understanding that price increases will be at least matched. Thus, departure from that behavior ought to induce either a breakdown of collusion or a more calculated punishment. The restrictiveness of the condition is really that it is common knowledge as to the low continuation payoff that ensues after a departure from price-matching plus behavior. Though any punishment would work for our analysis, a sophisticated punishment would have to be justified in terms of how the punishment is common knowledge. I feel it is more consistent with the spirit of the enterprise to simply assume a departure results in a breakdown of collusion rather than a sophisticated punishment, even though results are not dependent on that specification.

The next feature of the PMP property to consider is that a firm does not price in excess of $\bar{p}$, which means that it will follow price increases only as high as $\bar{p}$ and, as a price leader, will not raise price beyond $\bar{p}$. It is surely compelling for a firm to have some upper bound to how high it will price; for example, it would be nonsensical to follow a price increase to the point that market demand is zero or even to where it is above the monopoly price. However, this assumption goes further in that the upper bound is common to firms, and is commonly known. While strong, I believe it is necessary for the ensuing results. As shown in Lemma 1, A1 implies that this upper bound on price matching cannot be less than the static Nash equilibrium price and cannot exceed the highest equilibrium price (with the grim punishment).

Lemma 1 If $\bar{p} \notin\left\{p^{N}, \ldots, \widetilde{p}\right\}$ then there do not exist strategies consistent with $A 1$ : $\Sigma_{i}\left(\infty, \Delta^{P M P}\right)=\varnothing$.

The results of Section 4 require no further restriction on $\bar{p}$ other than $\bar{p} \in\left\{p^{N}, \ldots, \widetilde{p}\right\}$, while the results of Section 5 are unchanged as long as $\bar{p}$ is at least as high as $p^{*}$. However, it'll make for an easier presentation if it is assumed that the upper bound on price matching is the highest level consistent with A1. 
Assumption A2: $\bar{p}=\widetilde{p}$.

One could imagine that $\widetilde{p}$ might be focal given that it is the highest feasible value of $\bar{p}$ and that higher values are more profitable for all firms. From hereon, $S^{P M P}$ will refer to when $\bar{p}=\widetilde{p}$.

Consistent with the focus on the dynamic process by which firms come to coordinate on supracompetitive prices, it is assumed that they start out with prices at competitive levels: $\left(p_{1}^{0}, \ldots, p_{n}^{0}\right)=\left(p^{N}, \ldots, p^{N}\right)$ (though results are robust to this assumption).

Before moving on, it is useful to ask why it isn't reasonable to assume there are mutual beliefs that firms use some typical punishment strategy and price immediately at $\widetilde{p}$. So, let us consider firm $i$ using a grim trigger strategy: i) price at $p^{N}$ in periods $1, \ldots, t_{i}-1$; ii) price at $\widetilde{p}$ in period $t_{i}$; ii) price at $\widetilde{p}$ in period $t\left(>t_{i}\right)$ if all firms priced at $\widetilde{p}$ in periods $t=t_{i}, \ldots, t-1$; and iii) price at $p^{N}$ in period $t\left(>t_{i}\right)$ otherwise. Even if one could plausibly argue how firms would achieve mutual beliefs regarding this strategy, collusive prices will emerge if and only if $t_{1}=\cdots=t_{n}$ so that there is mutual beliefs as to when exactly to start pricing at a collusive level. It is then an open question whether reasonable assumptions on mutual beliefs can be made to result in firms pricing at $\widetilde{p}$.

\section{Collusive Price is Constrained}

\subsection{An Upper Bound on Price}

To begin, Lemma 2 shows that if a firm believes other firms use PMP-compatible strategies then it is optimal for that firm to also use a PMP-compatible strategy. In other words, the set $S^{P M P}$ is closed under the best reply operator.

Lemma 2 If a firm's beliefs are PMP-consistent then sequential rationality implies that the firm's strategy lies in $S^{P M P}: \rho_{i}\left(\Delta^{P M P}\right) \subset S^{P M P}$. 
Lemma 3 establishes that strong-delta-rationalizable strategies exist.

Lemma 3 If A1-A2 hold then $\Sigma_{i}\left(\infty, \Delta^{P M P}\right)$ is non-empty.

Turning to one of the paper's main results, Theorem 4 shows that common knowledge that firms are sequentially rational and use strategies satisfying the PMP property implies that price is bounded above by (approximately) $p^{*}$.

Theorem 4 If A1-A2 hold then $\left\{\left(p_{1}^{t}, \ldots, p_{n}^{t}\right)\right\}_{t=1}^{\infty}$ is weakly increasing over time and there exists finite $T$ such that $p_{1}^{t}=\cdots=p_{n}^{t}=\widehat{p} \forall t \geq T$ where $\widehat{p} \leq p^{*}+\varepsilon$.

In explaining the basis for Theorem 4, first note that while A1 leaves unspecified whether some firm will initiate a price increase, it is fully consistent with A1 for a firm to be a price leader. For example, if a firm believed other firms would not raise price then it would be rational for it to increase price (as long as the current price is not too high). The issue is how far would it go in raising price. If the firm expected that its price increase would only be met and never exceeded by a rival (for example, rivals are believed to only match price increases) then it would not want to raise price above (approximately) $p^{*}{ }^{19}$ Recall that $p^{*}$ is the price at which a firm, if it were to raise price from $p^{*}$ to any higher level (call it $p^{\prime}$ ), it would lose more in current profit (because of lower demand from pricing above the level $p^{*}$ set by its rivals) than it would gain in future profit (from all other firms raising price to $p^{\prime}$ ). Thus, a firm that believed its rivals would never initiate price increases would not raise price beyond $p^{*}$. However, a firm might be willing to lead a price increase above $p^{*}$ if it believed it would induce a rival to further increase price; for example, if the firm believed that firms would take turns leading price increases. Theorem 4 shows that cannot happen. Let me explain why.

\footnotetext{
${ }^{19}$ In discussing results, I will generally refer to the upper bound as $p^{*}$ rather than $p^{*}+\varepsilon$ since $\varepsilon$ is presumed to be small.
} 
By A1 and Lemma 1, a firm will never price above $\widetilde{p}$. If $\widetilde{p}>p^{*}$ then it furthermore means that a firm would never raise price to $\widetilde{p}$ since such a price increase would only induce its rivals to match that price; it would not induce them to further raise price. Thus, if a firm is sequentially rational and believes the other firms use PMPcompatible strategies then it will not raise price to $\widetilde{p}$. This puts an upper bound on price of $\widetilde{p}-\varepsilon$. We next build on that result to argue that $\widetilde{p}-2 \varepsilon$ is an upper bound on price. Given mutual beliefs regarding sequential rationality and PMP-consistent beliefs, firm $i$ then believes firm $j(\neq i)$ is sequentially rational and that firm $j$ believes firm $k$ uses a PMP-compatible strategy (for all $k \neq j$ ); hence, firm $i$ knows that firm $j$ will not raise price to $\widetilde{p}$. This means that firm $i$ knows that if it raises price to $\widetilde{p}-\varepsilon$ that this price increase will only be matched and not exceeded, which then makes a price increase to $\widetilde{p}-\varepsilon$ unprofitable (as long as $\widetilde{p}-\varepsilon>p^{*}$ ). Given that all firms are not willing to raise price to $\widetilde{p}-\varepsilon$ then $\widetilde{p}-2 \varepsilon$ is an upper bound on price. The proof is completed by induction to end up with the conclusion that a firm would never raise price to a level exceeding $p^{*}$. Hence, price is bounded above by $p^{*}$.

In deriving this upper bound, the punishment for deviation from (at least) matching price is reversion to a stage game Nash equilibrium. If firms had mutual beliefs regarding a grim trigger strategy (so that the punishment is the same as in a PMPcompatible strategy), firms could sustain a price as high as $\widetilde{p}$. With the more limited mutual beliefs that the strategy profile lies in $S^{P M P}$, price can only rise as high as $p^{*}$ which the next result shows is strictly less than $\widetilde{p}$.

Theorem $5 p^{*} \in\left(p^{N}, \widetilde{p}\right)$.

Recall that $p^{*}$ is the price at which the reduction in current profit from a marginal increase in a firm's price is exactly equal in magnitude to the rise in the present value of the future profit stream when that higher price is matched by all firms for the infinite future. Equivalently, $p^{*}$ is the price at which the increase in current profit from a marginal decrease in price to $p^{*}-\varepsilon$ is exactly equal in magnitude to the fall 
in the present value of the future profit stream when the firm's rivals lower price to $p^{*}-\varepsilon$ (when $\varepsilon$ is small). In comparison, $\widetilde{p}$ is the price for a firm at which the increase in current profit from a marginal decrease in price is exactly equal in magnitude to the fall in the present value of the future profit stream when the firm's rivals lower price to $p^{N} \cdot{ }^{20}$ Given that the punishment is more severe in the latter case, it follows that the maximal sustainable price is higher: $\widetilde{p}>p^{*} .^{21}$

With common knowledge that the strategy profile lies in $S^{P M P}$, the steady-state price is bounded above by $p^{*}$ even though higher prices are sustainable. In other words, if firms started at a price of $\widetilde{p}$ then such a price would persist. But if firms start with prices below $p^{*}$, such as at the non-collusive price $p^{N}$, then prices will not go beyond $p^{*}$, even though higher prices are sustainable. The obstacle is that it is not in the interests of any firm to lead a price increase beyond $p^{*}$. Thus, with only mutual understanding that the strategy profile lies in $S^{P M P}$, what is constraining how high price can go is the trade-off a firm faces when it acts as a price leader: It foregoes current demand and profit in exchange for higher future profit from its rivals having raised their prices to match its price increase. ${ }^{22}$ This is to be contrasted

\footnotetext{
${ }^{20}$ That is, $\widetilde{p}$ is the highest price for which a firm incentive compatibility constraint (1), holds. For this discussion, suppose $\widetilde{p}<p^{M}$.

${ }^{21}$ Note that Theorems 4 and 5 are robust to the form of the punishment. $p^{*}$ is independent of the punishment and, given another punishment, $\widetilde{p}$ would just be the highest sustainable price with that punishment.

${ }^{22}$ Wang (2009) provides indirect evidence of the costliness of price leadership. In a retail gasoline market in Perth, Australia, Shell was the price leader over $85 \%$ of the time until a new law increased the cost of price leadership, after which the three large firms - BP, Caltex, and Shell - much more evenly shared the role of price leader. The law specified that every gasoline station was to notify the government by $2 \mathrm{pm}$ of its next day's retail prices, and to post prices on its price board at the start of the next day for a duration of at least 24 hours. Hence, a firm which led in price could not expect its rivals to match its price until the subsequent day. The difference between price being matched in an hour and in a day is actually quite significant given the high elasticity of firm demand in the retail gasoline market. For the Quebec City gasoline market, Clark and Houde (2011, p. 20) find that "a station that posts a price more than 2 cents above the minimum price in the city loses
} 
with equilibrium where what limits how high is price is the condition that a firm finds it unprofitable to undercut it. While coordination, in a sense, comes for free with equilibrium, limited mutual understanding makes the coordination on price the constraining factor, not the stability of the price which is eventually coordinated upon. This insight may have important implications for comparative statics since it is a different condition determining the collusive price. ${ }^{23}$

As an empirical aside, this cost to price leadership could be avoided if a firm were to instead announce a future price increase, rather than enact a price increase. Such an announcement could, in principle, allow firms to simultaneously raise price. In the ATPCO case (Borenstein, 1994), an airline would announce a fare increase with a future ticket date (which meant that a consumer could not purchase a ticket at that fare until that future date) and wait for other airlines to make identical announcements. If they did then airlines would implement the future fare increase on the same day, and if they did not then the airline would retract its proposed fare increase. Though leading with an advance price announcement would seem to dominate leading with price, the use of price - not price announcements - to coordinate on price is well-documented in many markets. Markham (1951) and Scherer (1980, Chapter 6) provide some historical examples and some recent cases include retail gasoline in the U.S. (Lewis, 2012), wholesale gasoline in Italy (Andreoli-Versbach and Franck, 2015), and supermarkets in Great Britain (Seaton and Waterson, 2013). One possible reason that price announcements may not be used is that there may not always be a public forum through which announcements could be made and a firm between $35 \%$ and $50 \%$ of its daily volume."

${ }^{23}$ The property that price falls short of the equilibrium price is similar to a finding in Lockwood and Thomas (2002). They consider a multi-player infinite horizon setting in which actions are irreversible; that is, the minimum element of player $i$ 's period $t$ action set is the action the player selected in period $t-1$. The equilibrium path is uniformly bounded above by the first-best for basically the same reasons that price converges to a value less than $\widetilde{p}$. I want to thank Thomas Mariotti for pointing out this connection. 
would be ensured that all relevant competitors would learn of it. Even when advance price announcements are available as an option, it is useful to know the implications of taking them off of the table as has been done by some competition authorities because of anti-competitive concerns. The aforementioned airlines case resulted in a tenyear consent decree with the U.S. Department of Justice which prevented the use of advance price announcements (though with some special exceptions). More recently, Australia has prohibited certain forms of advance announcements on interest rates in the banking industry in order to discourage collusion. ${ }^{24}$ Between the possible lack of a public forum, concerns about drawing the attention of the competition authority, or outright prohibition of price announcements, there are many reasons for firms to try to coordinate through actual prices rather than through price announcements. Leadership by price has a long and well-documented history.

\subsection{Price Can Be Competitive or Supracompetitive}

By Theorem 4, if it is common knowledge that firms are sequentially rational and their strategies satisfy the PMP property then price is bounded above by $p^{*}$. But is $p^{*}$ the least upper bound? And is there a lower bound on price exceeding $p^{N}$ ? The purpose of the current section is to show, by way of example, that it is consistent with A1-A2 for price to converge to $p^{*}$ but also to fail to rise above $p^{N}$. Thus, a tighter result than Theorem 4 will require additional assumptions, which is a matter taken up in Section 5.

For the duopoly case, suppose the price set is composed of just three elements, $\left\{p^{N}, p^{\prime}, p^{M}\right\}$, and $p^{\prime} \equiv\left(p^{M}+p^{N}\right) / 2$. Assume $\delta$ is sufficiently close to one so that $p^{*}=$ $\widetilde{p}=p^{M}{ }^{25}$ Consider the following pair of functions which map from $\max \left\{p_{1}^{t-1}, p_{2}^{t-1}\right\}$

\footnotetext{
${ }^{24}$ www.accc.gov.au/business/anti-competitive-behaviour/price-signalling

${ }^{25}$ In this example, $p^{*}$ is defined for when the feasible price set is $\left\{p^{N}, p^{\prime}, p^{M}\right\}$ rather than $\Re_{+}$. This, however, is a good approximation when $\delta \simeq 1$ as then $p^{*} \simeq p^{M}$ when the price set is $\Re_{+}$. Of course, if $\delta \simeq 1$ then $\widetilde{p}=p^{M}$.
} 
to current price $p_{i}^{t}$ :

$$
\begin{aligned}
& S^{L}\left(p^{N}\right)=p^{\prime}, S^{L}\left(p^{\prime}\right)=p^{M}, S^{L}\left(p^{M}\right)=p^{M} \\
& S^{F}\left(p^{N}\right)=p^{N}, S^{F}\left(p^{\prime}\right)=p^{\prime}, S^{F}\left(p^{M}\right)=p^{M}
\end{aligned}
$$

$S^{L}$ (where $L$ denotes "leader") has a firm raise price to $p^{\prime}$ when the lagged maximum price is $p^{N}$, to $p^{M}$ when the lagged maximum price is $p^{\prime}$, and to price at $p^{M}$ when the lagged maximum price is $p^{M} . S^{F}$ (where $F$ denotes "follower") has a firm's price equal the lagged maximum price. When $S^{L}\left(\right.$ or $\left.S^{F}\right)$ is referred to as a strategy, it is meant that the specification in (5) applies when both firms have priced at least as high as the previous period's maximum price in all past periods, and otherwise a firm prices at $p^{N}$. Thus, these strategies satisfy the PMP property. Sufficient conditions are provided in the Online Appendix for $\left(S^{L}, S^{F}\right)$ to be a subgame perfect equilibrium.

If $\left(S^{L}, S^{F}\right)$ is a subgame perfect equilibrium, it is easy to argue that both strategies satisfy A1-A2. If, for all histories, a firm's beliefs assign probability one to its rival using strategy $S^{F}$ then $S^{L}$ is sequentially rational for those beliefs; and if a firm's beliefs assign probability one to its rival using strategy $S^{L}$ then $S^{F}$ is sequentially rational for those beliefs. Therefore, $S^{L}$ and $S^{F}$ are consistent with $\mathcal{A}^{0}$. Mutual strong belief in $\mathcal{A}^{0}$ implies that firms' beliefs have support over strategies consistent with $\mathcal{A}^{0}$. Hence, $S^{L}$ and $S^{F}$ are consistent with $\mathcal{A}^{1}$, and so forth.

Any price path consistent with firms deploying a strategy pair from $\left\{S^{L}, S^{F}\right\}^{2}$ is then consistent with A1-A2. For example, a price path of $\left(\left(p^{\prime}, p^{N}\right),\left(p^{M}, p^{\prime}\right)\left(p^{M}, p^{M}\right), \ldots\right)$ is consistent with A1-A2. It is achieved by firm 1 using $S^{L}$ based on the belief that firm 2 uses $S^{F}$, and firm 2 using $S^{F}$ based upon the belief that firm 1 uses $S^{L}$. However, it is also the case that a price path of $\left(\left(p^{N}, p^{N}\right), \ldots\right)$ is consistent with A1-A2. It occurs when each firm's strategy is $S^{F}$ which is sequentially rational if, for all histories, a firm believes the other firm uses $S^{L}$ (in the future). Thus, common knowledge of sequential rationality and that prices increases will be at least matched does not 
imply supracompetitive prices; either competitive or supracompetitive prices could ensue.

\section{Supracompetitive Prices Emerge}

As just described, competitive pricing can occur - in spite of price matching being common knowledge - because firms' beliefs are inconsistent; each believes someone else will lead on price and each takes the role of follower with no price leader emerging. However, if firms could learn over time about rivals' strategies then perhaps a firm would learn that other firms are not likely to lead which would could induce it to raise price. To pursue this approach, I draw on a result of Kalai and Lehrer (1993) regarding the learning of strategies in an infinitely repeated game.

By A1-A2, firms use strategies in $\Sigma_{i}\left(\infty, \Delta^{P M P}\right)$ and these are sequential best replies to beliefs which put unit mass on those strategies in $\Sigma_{i}\left(\infty, \Delta^{P M P}\right)$ consistent with the history: if $S_{-i}(h) \cap \Sigma_{i}\left(\infty, \Delta^{P M P}\right) \neq \varnothing$ then $\mu^{i}\left(\Sigma_{i}\left(\infty, \Delta^{P M P}\right) \mid h\right)=1$. We can then think of firm $i$ as having a prior set of beliefs on other firms' strategies with support $\Pi_{j \neq i} \Sigma_{j}\left(\infty, \Delta^{P M P}\right)$. Kalai and Lehrer (1993) make some assumptions about those prior beliefs and on how those beliefs are updated. To describe the former, let $\omega(s) \in\left(\Omega^{\infty}\right)^{n}$ denote the outcome path induced by a strategy profile $s \in S^{n}$ in which case $\cup_{s \in \Pi_{j=1}^{n} \Sigma_{j}\left(\infty, \Delta^{P M P}\right)} \omega(s)$ is the set of outcome paths induced by a strategy profile consistent with A1-A2. Next define $\xi(s) \equiv\left\{s^{\prime} \in \Pi_{j=1}^{n} \Sigma_{j}\left(\infty, \Delta^{P M P}\right): \omega\left(s^{\prime}\right)=\omega(s)\right\}$ as the set of strategy profiles (consistent with A1-A2) that induce the same outcome path as $s$. It is shown in Appendix B that $\cup_{s \in \Pi_{j=1}^{n} \Sigma_{j}\left(\infty, \Delta^{P M P}\right)} \omega(s)$ is countable and, therefore, $\cup_{s \in \Pi_{j=1}^{n} \Sigma_{j}\left(\infty, \Delta^{P M P}\right)} \xi(s)$ is a countable partition of $\Pi_{j=1}^{n} \Sigma_{j}\left(\infty, \Delta^{P M P}\right)$.

The first assumption I now make is that prior beliefs assign positive probability to every element of that partition or, alternatively stated, prior beliefs on outcome paths consistent with A1-A2 have full support. ${ }^{26}$

\footnotetext{
${ }^{26}$ In Kalai and Lehrer (1993), Assumption 3 (which is referred to as the "Grain of Truth") takes
} 
Assumption A3: $\mu^{i}\left(\xi(s) \mid h^{0}\right)>0, \forall s \in \Pi_{j=1}^{n} \Sigma_{j}\left(\infty, \Delta^{P M P}\right), \forall i$.

The next assumption is that firms are Bayesian when they update their prior beliefs.

Assumption A4: In response to the realized price path, a firm updates its beliefs as to other firms' strategies using Bayes Rule.

A firm starts with prior beliefs about other firms' strategies which, along with the firm's own sequentially rational best response to those beliefs, implies prior beliefs about the price path. By A1-A2, these prior beliefs have full support in the sense that they assign positive probability to every outcome path that can result from strategies consistent with mutual understanding that each firm is sequentially rational and believes other firms use PMP-compatible strategies. Given the strategy profile that firms adopted given their prior beliefs, prices will be chosen and an outcome path will emerge. Come period $t$, firms will have observed the first $t-1$ periods of the true underlying price path and each will update its beliefs as to other firms' strategies and the resultant future price path using Bayes Rule. By sequential rationality, it is required that each firm's strategy is optimal at that point. By the result of Kalai and Lehrer (1993), this process will entail firms eventually having beliefs over the future path of play that are "close" to the true future path of play. Theorem 6 shows that an implication of this learning of the future price path is that firms are almost sure to eventually price close to the supracompetitive price $p^{*}$.

the form: Players assign positive prior probability to a strategy profile which induces an outcome path consistent with the outcome path that actually occurs. Because there is an uncountable number of outcome paths in their setting, they cannot assume prior beliefs have full support. The "Grain of Truth" assumption has been subject to the criticism that there is a circularity akin to that with equilibrium analysis. In our case, the additional structure provided by A1 allows us to avoid that circularity. With a countable number of outcome paths, a full support assumption can be made. I want to thank Phil Reny for conjecturing that the set of outcome paths consistent with A1 is countable and Sea Moon (Simon) Cho for proving that conjecture to be true. 
Theorem 6 Assume A1-A4. For all $\eta>0$, there exists $T$ such that, with probability of at least $1-\eta, p_{1}^{t}=\cdots=p_{n}^{t}=\widehat{p} \forall t \geq T$ where $\widehat{p} \in\left\{p^{*}-\varepsilon, p^{*}, p^{*}+\varepsilon\right\}$.

By Theorem 6, learning implies supracompetitive prices will eventually emerge even though firms only have mutual understanding over price matching and not over who will lead. To understand why prices must converge to (approximately) $p^{*}$, suppose they did not and instead converged to $\widehat{p}$ where $\widehat{p}<p^{*}-\varepsilon$. By the result of Kalai and Lehrer (1993), firms will eventually believe with high probability that the future path has all firms price at $\widehat{p}$. But since $\widehat{p}<p^{*}-\varepsilon$ then $\phi(\widehat{p}, \ldots, \widehat{p})>\widehat{p}$ in which case a firm would find it optimal to raise price above $\widehat{p}$ given it expects other firms to respond by at least matching that price increase. ${ }^{27}$ In other words, if a firm eventually came to believe that the other firms were extremely unlikely to raise price and the current price is less than $p^{*}-\varepsilon$, then a firm would find it profitable to act as a price leader. Thus, learning the future price path prevents firms from getting mired in a miscoordination in which all firms do not act as a price leader because each anticipates that other firms will do so. ${ }^{28}$

\section{Concluding Remarks}

In his classic examination of imperfect competition, Chamberlain (1948) argued that collusion would naturally emerge because each firm would recognize the incentive to maintain a collusive price, rather than undercut its rivals' prices and bring forth retaliation. We now know that it is a non-trivial matter for firms to coordinate on a collusive solution because there are so many collusive equilibria. This multiplicity poses a challenge for firms to achieve mutual understanding with respect to the collusive strategy profile, and this challenge is exacerbated should firms avoid direct and

\footnotetext{
${ }^{27}$ Recall that $\phi$ is a firm's optimal period $t$ price when it expects other firms to price in period $t$ at the maximum price of period $t-1$ and all future prices equal the maximum price of period $t$.

${ }^{28}$ The Online Appendix provides an example in which prior beliefs are specified and for which sequentially rational strategies and posterior beliefs are explicitly solved.
} 
unconstrained communication. All of this naturally raises the question of how much mutual understanding must firms have in order to effectively collude.

To my knowledge, this paper is the first to explore the relationship between mutual understanding among firms and the coordination on supracompetitive outcomes. Assuming that the game and firms' rationality is common knowledge, I investigated the implications of common knowledge that price increases will be at least matched and failure to do so results in a return to competition. It was shown there is an upper bound on price that is strictly below what equilibrium sustains (given the same underlying punishment). However, this level of mutual beliefs is not sufficient to ensure success in colluding as both competitive and supracompetitive price paths could ensue. If, in addition, firms update their beliefs on other firms' strategies using Bayes Rule and their prior beliefs have full support on those price paths consistent with possible beliefs on strategies then supracompetitive prices will occur almost for sure. Thus, mutual understanding that price increases will be matched - but not about who will lead on price, at what time, and at what level - can be sufficient for firms to effectively collude.

This paper initiates a research program to address the following question: How much and what kind of mutual understanding is enough for firms to effectively collude? The execution of this program involves specifying mutual beliefs regarding firms' environment, their rationality, and their strategies, and then deriving the implications for firm behavior. Here are two other scenarios to which the approach could be applied. Bell Atlantic Corp. v. Twombly, 550 U.S. 544 (2007) was a case in which incumbent local exchange carriers (ILECs) - also known as the Regional Bell Operating Companies - were accused of an agreement to stay out of each other's geographic market. Regulation had originally prevented the ILECs from engaging in such entry but that prohibition was removed with deregulation in 1996; still, there was no entry even though the plaintiffs argued that it was profitable. As opposed to the setting explored in this paper - where firms begin at a competitive outcome and 
the issue is whether price leadership and matching can take them to higher prices - the ILECs began at a supracompetitive outcome. In such a scenario, how much and what kind of mutual understanding is required for firms to maintain a collusive scheme of exclusive territories? Another setting of interest involves bidding rings at auctions. In United States v. Champion Intl. Corp., 557 F.2d 1270 (9th Cir., 1977), the market involved lumber companies bidding for timber offered for sale by the U.S. Forest Service. A pattern of aggressive bidding was suddenly replaced with each auction having only one serious bidder. The trial court found no evidence of meetings to initiate this change in behavior. ${ }^{29}$ How much and what kind of common beliefs is sufficient to implement and sustain such a bid rotation scheme?

By identifying the relationship between firms' mutual understanding and their ability to effectively collude, such a research program will identify what types of mutual beliefs ought to raise concerns to competition authorities. Having identified those mutual beliefs that support collusion, communication practices likely to generate those mutual beliefs are a target for prohibition. In this manner, economic theory can contribute to identifying the boundaries of unlawful collusion.

\section{Appendix A}

Proof of Lemma 1: Suppose $\bar{p}<p^{N}$. Consider a history through period $t-1$ such that $\max \left\{p_{1}^{t-1}, \ldots, p_{n}^{t-1}\right\}=\bar{p}$. Given a firm's beliefs lie in $\Delta^{P M P}$, it then expects other firms to price at $\bar{p}$ for the infinite future as long as no firm lowers price. Thus, a firm that prices according to a PMP-compatible strategy, which means pricing at $\bar{p}$, can expect a payoff of $\left(\frac{1}{1-\delta}\right) \pi(\bar{p}, \ldots, \bar{p})$. Alternatively, a firm could price at $\psi(\bar{p}, \ldots, \bar{p})(>\bar{p})$ and earn $\left(\frac{1}{1-\delta}\right) \pi(\psi(\bar{p}, \ldots, \bar{p}), \bar{p}, \ldots, \bar{p})$, again given its beliefs on other

\footnotetext{
${ }^{29}$ Quoting from the 9th Circuit Court: "The government was unable to introduce direct evidence of an express agreement, but argues that the circumstantial evidence proved the existence of the tacit agreement found by the judge. We agree."
} 
firms' strategies are in $\Delta^{P M P}$. From our assumptions, $\bar{p}<p^{N}$ implies

$$
\left(\frac{1}{1-\delta}\right) \pi(\psi(\bar{p}, \ldots, \bar{p}), \bar{p}, \ldots, \bar{p})>\left(\frac{1}{1-\delta}\right) \pi(\bar{p}, \ldots, \bar{p}) .
$$

Hence, it is not sequentially rational to price at $\bar{p}$ for this history. From this it follows that the set of strategies that are sequentially rational for some beliefs in $\Delta^{P M P}$, $\Sigma_{i}\left(1, \Delta^{P M P}\right)$, excludes strategies for which the price is $\bar{p}$ when the preceding period's maximal price is $\bar{p}$, as long as $\bar{p}<p^{N}$. As this is contrary to what is prescribed by PMP-compatible strategies, $\Sigma_{i}\left(1, \Delta^{P M P}\right) \cap S^{P M P}=\varnothing$.

The next step is to use this property $-\Sigma_{i}\left(1, \Delta^{P M P}\right) \cap S^{P M P}=\varnothing$ - to show that there do not exist strong-delta-rationalizable strategies when $\bar{p}<p^{N}$. Consider level 2 beliefs:

$$
\begin{aligned}
& \Phi^{i}\left(2, \Delta^{P M P}\right) \\
= & \left\{\mu^{i} \in \Phi^{i}\left(1, \Delta^{P M P}\right): \forall h \in \mathcal{H}, S_{-i}(h) \cap \Sigma_{-i}\left(1, \Delta^{P M P}\right) \neq \varnothing \Rightarrow \mu^{i}\left(\Sigma_{-i}\left(1, \Delta^{P M P}\right) \mid h\right)=1\right\}
\end{aligned}
$$

Consider the null history $h^{0}$ (that is, the period 0 history) so that

$$
S_{-i}\left(h^{0}\right) \cap \Sigma_{-i}\left(1, \Delta^{P M P}\right)=S_{-i} \cap \Sigma_{-i}\left(1, \Delta^{P M P}\right)=\Sigma_{-i}\left(1, \Delta^{P M P}\right) \neq \varnothing
$$

and, therefore, it follows from $(6)$ that $\mu^{i}\left(\Sigma_{-i}\left(1, \Delta^{P M P}\right) \mid h^{0}\right)=1$. Hence, $\Phi^{i}\left(2, \Delta^{P M P}\right)=$ $\varnothing$ because $\mu^{i} \in \Phi^{i}\left(1, \Delta^{P M P}\right) \subset \Delta^{P M P}$ in (6) implies beliefs put unit mass on $S^{P M P}$, while $\Sigma_{i}\left(1, \Delta^{P M P}\right) \cap S^{P M P}=\varnothing$ and $\mu^{i}\left(\Sigma_{-i}\left(1, \Delta^{P M P}\right) \mid h\right)=1$ in (6) implies zero mass is put on $S^{P M P}$. It follows from $\Phi^{i}\left(2, \Delta^{P M P}\right)=\varnothing$ that $\Sigma_{i}\left(3, \Delta^{P M P}\right)=\varnothing$, and, therefore, $\Sigma_{i}\left(\infty, \Delta^{P M P}\right)=\varnothing$. In other words, firm $i$ believing that firm $j$ is sequentially rational is inconsistent with also believing firm $j$ uses a PMP-compatible strategy. I conclude that if $\bar{p}<p^{N}$ then $\Sigma_{i}\left(\infty, \Delta^{P M P}\right)=\varnothing$.

Now suppose $\bar{p}>\widetilde{p}\left(>p^{N}\right)$ and again consider a history through period $t-1$ such that $\max \left\{p_{1}^{t-1}, \ldots, p_{n}^{t-1}\right\}=\bar{p}$. Given a firm's beliefs lie in $\Delta^{P M P}$, it expects other firms to price at $\bar{p}$ for the infinite future as long as no firm lowers price. Thus, a firm that prices according to a PMP-compatible strategy, which means pricing at $\bar{p}$, can expect 
a payoff of $\left(\frac{1}{1-\delta}\right) \pi(\bar{p}, \ldots, \bar{p})$. Alternatively, a firm could price at $\psi(\bar{p}, \ldots, \bar{p})(<\bar{p})$ and earn $\pi(\psi(\bar{p}, \ldots, \bar{p}), \bar{p}, \ldots, \bar{p})$ in the current period. By the definition of $\widetilde{p}$,

$$
\pi(\psi(\bar{p}, \ldots, \bar{p}), \bar{p}, \ldots, \bar{p})+\left(\frac{\delta}{1-\delta}\right) \pi^{N}>\left(\frac{1}{1-\delta}\right) \pi(\bar{p}, \ldots, \bar{p}),
$$

so it is not sequentially rational to price at $\bar{p}$ for this history. The remainder of the proof is the same as for when $\bar{p}<p^{N}$ and serves to show that if $\bar{p}>\widetilde{p}$ then $\Phi^{i}\left(2, \Delta^{P M P}\right)=\varnothing$ and, therefore, $\Sigma_{i}\left(\infty, \Delta^{P M P}\right)=\varnothing$.

A useful property of other firms using PMP-compatible strategies is that a lower bound on a rational firm's period $t$ continuation payoff is the payoff associated with all firms pricing at $\min \left\{\max \left\{p_{1}^{t-1}, \ldots, p_{n}^{t-1}\right\}, \widetilde{p}\right\}$ in all periods. Intuitively, if the rivals to firm $i$ are using PMP-compatible strategies then they will price at least as high as $\min \left\{\max \left\{p_{1}^{t-1}, \ldots, p_{n}^{t-1}\right\}, \widetilde{p}\right\}$ in all ensuing periods, as long as firm $i$ does not violate the PMP property and induce a shift to $p^{N}$. Hence, firm $i$ can at least earn the profit from all firms (including $i$ ) pricing at $\min \left\{\max \left\{p_{1}^{t-1}, \ldots, p_{n}^{t-1}\right\}, \widetilde{p}\right\}$. The proof of Lemma 7 is in the Online Appendix.

Lemma 7 Suppose firm $i$ uses strategy $\widehat{s}_{i}$. If firm $i$ is sequentially rational and has PMP-consistent beliefs then its expected continuation payoff, $U_{i}\left(\widehat{s}_{i}, \mu^{i}(s \cdot \mid h)\right)$, satisfies

$U_{i}\left(\widehat{s}_{i}, \mu^{i}\left(\cdot \mid h^{t}\right)\right) \geq \frac{\pi\left(\min \left\{\max \left\{p_{1}^{t-1}, \ldots, p_{n}^{t-1}\right\}, \widetilde{p}\right\}, \ldots, \min \left\{\max \left\{p_{1}^{t-1}, \ldots, p_{n}^{t-1}\right\}, \widetilde{p}\right\}\right)}{1-\delta}$,

for all $h^{t}$ such that $p_{j}^{\tau} \geq \min \left\{\max \left\{p_{1}^{\tau-1}, \ldots, p_{n}^{\tau-1}\right\}, \widetilde{p}\right\} \forall j, \forall \tau \leq t-1$.

Proof of Lemma 2: Suppose $h^{t}$ is such that

$$
p_{j}^{\tau}<\min \left\{\max \left\{p_{1}^{\tau-1}, \ldots, p_{n}^{\tau-1}\right\}, \widetilde{p}\right\} \text { for some } j \text { and some } \tau \leq t-1 \text {. }
$$

A PMP-compatible strategy for firm $i$ has a firm price at $p^{N}$ in the current and all future periods. Thus, if firm $i$ 's beliefs are PMP-consistent then pricing at $p^{N}$ is 
clearly optimal as firm $i$ believes all other firms will price at $p^{N}$ forever. Hence, a PMP-compatible strategy is uniquely optimal for firm $i$ for those histories.

For the remainder of the proof, consider $h^{t}$ such that

$$
p_{j}^{\tau} \geq \min \left\{\max \left\{p_{1}^{\tau-1}, \ldots, p_{n}^{\tau-1}\right\}, \widetilde{p}\right\} \forall j, \forall \tau \leq t-1
$$

To prove this lemma, it'll be shown that, for any strategy for firm $i$ that is not in $S^{P M P}$, there exists a strategy in $S^{P M P}$ which yields a strictly higher payoff and, therefore, sequential rationality implies the use of a PMP-compatible strategy. Thus, as long as a firm believes the other firms are using PMP-compatible strategies then a PMP-compatible strategy is optimal.

Given $p_{j}^{\tau} \geq \min \left\{\max \left\{p_{1}^{\tau-1}, \ldots, p_{n}^{\tau-1}\right\}, \widetilde{p}\right\} \forall j, \forall \tau \leq t-1$, firm $i$ 's strategy can violate the PMP property (and thus not lie in $S^{P M P}$ ) either by pricing above $\widetilde{p}$ or below $\max \left\{p_{1}^{t-1}, \ldots, p_{n}^{t-1}\right\}$. Let us begin by considering a PMP-incompatible strategy that has firm $i$ price at $p^{\prime}>\widetilde{p}$. When its rivals price at $\mathbf{p}_{-i}^{t}$, a PMP-compatible strategy that has firm $i$ price at $\widetilde{p}$ is more profitable than pricing at $p^{\prime}$ iff:

$$
\pi\left(\widetilde{p}, \mathbf{p}_{-i}^{t}\right)+\left(\frac{\delta}{1-\delta}\right) \pi(\widetilde{p}, \ldots, \widetilde{p})>\pi\left(p^{\prime}, \mathbf{p}_{-i}^{t}\right)+\left(\frac{\delta}{1-\delta}\right) \pi(\widetilde{p}, \ldots, \widetilde{p})
$$

where recall that the other firms will only follow price as high as $\widetilde{p}$. (7) holds iff

$$
\pi\left(\widetilde{p}, \mathbf{p}_{-i}^{t}\right)>\pi\left(p^{\prime}, \mathbf{p}_{-i}^{t}\right)
$$

Given that $\mathbf{p}_{-i}^{t} \leq(\widetilde{p}, \ldots, \widetilde{p})$ and $p^{N}<\widetilde{p}$ then $\psi\left(\mathbf{p}_{-i}^{t}\right) \leq \psi(\widetilde{p}, \ldots, \widetilde{p})<\widetilde{p}$. By the strict concavity of $\pi$ in a firm's own price and that $\psi\left(\mathbf{p}_{-i}^{t}\right)<\widetilde{p}<p^{\prime},(8)$ is true.

Next consider a PMP-incompatible strategy that has firm $i$ price at $p^{\prime \prime}<\max \left\{p_{1}^{t-1}, \ldots, p_{n}^{t-1}\right\}$. Let us show that a PMP-compatible strategy that has firm $i$ price at $\max \left\{p_{1}^{t-1}, \ldots, p_{n}^{t-1}\right\}$ is more profitable than pricing at $p^{\prime \prime}$ for any $\mathbf{p}_{-i}^{t} \in\left[\max \left\{p_{1}^{t-1}, \ldots, p_{n}^{t-1}\right\}, \tilde{p}\right]^{n-1}$; that is, for any prices for the other firms assigned positive probability given PMP-consistent 
beliefs. ${ }^{30}$ A sufficient condition for the preceding claim to be true is:

$$
\begin{aligned}
& \pi\left(\max \left\{p_{1}^{t-1}, \ldots, p_{n}^{t-1}\right\}, \mathbf{p}_{-i}^{t}\right)+\left(\frac{\delta}{1-\delta}\right) \pi\left(\max \left\{\mathbf{p}_{-i}^{t}\right\}, \ldots, \max \left\{\mathbf{p}_{-i}^{t}\right\}\right) \\
> & \pi\left(p^{\prime \prime}, \mathbf{p}_{-i}^{t}\right)+\left(\frac{\delta}{1-\delta}\right) \pi^{N},
\end{aligned}
$$

where the LHS of (9) is a lower bound on the payoff from pricing at $\max \left\{p_{1}^{t-1}, \ldots, p_{n}^{t-1}\right\}$ and the RHS is the payoff from pricing at $p^{\prime \prime}$. In examining the LHS, note that $p_{i}^{t}=$ $\max \left\{p_{1}^{t-1}, \ldots, p_{n}^{t-1}\right\}$ and that the other firms' strategies are PMP-compatible imply $\max \left\{p_{1}^{t}, \ldots, p_{n}^{t}\right\}=\max \left\{\mathbf{p}_{-i}^{t}\right\}$. Using Lemma $7,\left(\frac{\delta}{1-\delta}\right) \pi\left(\max \left\{\mathbf{p}_{-i}^{t}\right\}, \ldots, \max \left\{\mathbf{p}_{-i}^{t}\right\}\right)$ is a lower bound on the future payoff, which gives us the LHS of (9). When

$$
\mathbf{p}_{-i}^{t}=\left(\max \left\{p_{1}^{t-1}, \ldots, p_{n}^{t-1}\right\}, \ldots, \max \left\{p_{1}^{t-1}, \ldots, p_{n}^{t-1}\right\}\right)
$$

(9) is

$$
\begin{aligned}
& \pi\left(\max \left\{p_{1}^{t-1}, \ldots, p_{n}^{t-1}\right\}, \ldots, \max \left\{p_{1}^{t-1}, \ldots, p_{n}^{t-1}\right\}\right) \\
& +\left(\frac{\delta}{1-\delta}\right) \pi\left(\max \left\{p_{1}^{t-1}, \ldots, p_{n}^{t-1}\right\}, \ldots, \max \left\{p_{1}^{t-1}, \ldots, p_{n}^{t-1}\right\}\right) \\
> & \pi\left(p^{\prime \prime}, \max \left\{p_{1}^{t-1}, \ldots, p_{n}^{t-1}\right\}, \ldots, \max \left\{p_{1}^{t-1}, \ldots, p_{n}^{t-1}\right\}\right)+\left(\frac{\delta}{1-\delta}\right) \pi^{N} .
\end{aligned}
$$

Note that $\max \left\{p_{1}^{t-1}, \ldots, p_{n}^{t-1}\right\} \in\left\{p^{N}, \ldots, \widetilde{p}\right\}$ where $\max \left\{p_{1}^{t-1}, \ldots, p_{n}^{t-1}\right\} \geq p^{N}$ follows from the assumption that $\left(p_{1}^{0}, \ldots, p_{n}^{0}\right)=\left(p^{N}, \ldots, p^{N}\right)$. (11) is then true for all $p^{\prime \prime}<$ $\max \left\{p_{1}^{t-1}, \ldots, p_{n}^{t-1}\right\}$ as it is the equilibrium condition for a grim trigger strategy with collusive price $\max \left\{p_{1}^{t-1}, \ldots, p_{n}^{t-1}\right\} .{ }^{31}$ Thus, (9) holds for (10).

To complete the proof, it will be shown that the LHS of (9) is increasing in $\mathbf{p}_{-i}^{t}$ at a faster rate than the RHS in which case (9) holds for all

$$
\mathbf{p}_{-i}^{t} \geq\left(\max \left\{p_{1}^{t-1}, \ldots, p_{n}^{t-1}\right\}, \ldots, \max \left\{p_{1}^{t-1}, \ldots, p_{n}^{t-1}\right\}\right)
$$

\footnotetext{
${ }^{30}$ Actually, it is shown to be only weakly as profitable when $\mathbf{p}_{-i}^{t}=(\widetilde{p}, \ldots, \widetilde{p})$.

${ }^{31}$ Recall that $\widetilde{p}$ is the highest price consistent with the grim trigger strategy being an equilibrium. Note that (11) holds with equality when $\max \left\{p_{1}^{t-1}, \ldots, p_{n}^{t-1}\right\}=\widetilde{p}$ and $p^{\prime \prime}=\psi(\widetilde{p}, \ldots, \widetilde{p})$ and otherwise is a strict inequality.
} 
The derivative with respect to $p_{j}^{t}, j \neq i$, of the LHS of (9) is

$\frac{\partial \pi\left(\max \left\{p_{1}^{t-1}, \ldots, p_{n}^{t-1}\right\}, \mathbf{p}_{-i}^{t}\right)}{\partial p_{j}}+\left(\frac{\delta}{1-\delta}\right) \frac{\partial \max \left\{\mathbf{p}_{-i}^{t}\right\}}{\partial p_{j}} \sum_{k=1}^{n} \frac{\partial \pi\left(\max \left\{\mathbf{p}_{-i}^{t}\right\}, \ldots, \max \left\{\mathbf{p}_{-i}^{t}\right\}\right)}{\partial p_{k}}$

and of the RHS of (9) is

$$
\frac{\partial \pi\left(p^{\prime \prime}, \mathbf{p}_{-i}^{t}\right)}{\partial p_{j}}
$$

(12) exceeds (13) because the second term in (12) is non-negative, given that $\mathbf{p}_{-i}^{t} \leq$ $\left(p^{M}, \ldots, p^{M}\right)$, and the first term of (12) exceeds (13) because $\max \left\{p_{1}^{t-1}, \ldots, p_{n}^{t-1}\right\}>p^{\prime \prime}$ and $\frac{\partial^{2} \pi}{\partial p_{i} \partial p_{j}}>0, j \neq i$.

Proof of Lemma 3: $\quad \Sigma_{i}\left(1, \Delta^{P M P}\right)=\rho_{i}\left(\Delta^{P M P}\right)$ and, by Lemma $2, \rho_{i}\left(\Delta^{P M P}\right) \subset$ $S^{P M P}$. Next note that $\Sigma_{i}\left(2, \Delta^{P M P}\right)=\rho_{i}\left(\Delta\left(\Pi_{j \neq i} \rho_{j}\left(\Delta^{P M P}\right)\right)\right) \subset S^{P M P}$, again ap-

plying Lemma 2; and so forth. Given that the set of sequential best replies, $\rho_{i}$, is non-empty (see Lemma 2.4 of Battigalli, 2003), the lemma is proved.

Proof of Theorem 4: Given each firm has PMP-consistent beliefs then, by Lemma 2, sequential rationality implies each firm's strategy is PMP-compatible. As firms' strategies are PMP-compatible, it immediately follows that each firm's price is weakly increasing. Given a finite price set and the boundedness and monotonicity of prices, prices converge in finite time. Hence, there exists $\widehat{p} \in\left\{p^{N}, \ldots, \widetilde{p}\right\}$ and finite $T$ such that $p_{1}^{t}=\cdots=p_{n}^{t}=\widehat{p}$ for all $t \geq T$. We then need to show that $\widehat{p} \leq p^{*}+\varepsilon$. If $p^{*}+\varepsilon \geq \widetilde{p}$ then, given that PMP-compatible strategies do not have firms pricing above $\widetilde{p}$, it is immediate that $\widehat{p} \leq p^{*}+\varepsilon$. For the remainder of the proof, suppose $p^{*}+\varepsilon<\widetilde{p}$.

Let me provide an overview of the proof. First it is shown that if a firm is sequentially rational and has PMP-consistent beliefs then it will not lead a price increase to $\widetilde{p}$. The reason is as follows. A firm would find it optimal to raise price above $p^{*}+\varepsilon$ only if it induced at least one of its rivals to enact further price increases (and not just match the firm's price); that is the defining property of $p^{*}$. However, 
if a firm believes its rivals will not price above $\widetilde{p}$ (which follows from having PMPconsistent beliefs) then it is not optimal for a firm to raise price to $\widetilde{p}$ because it can only expect its rivals to match a price of $\widetilde{p}$, not exceed it. This argument works as well to show that each of the other firms will not raise price to $\widetilde{p}$. Hence, there is an upper bound on price of $\widetilde{p}-\varepsilon$. The proof is completed by induction using the mutual beliefs in A1. If a firm believes its rivals will not price above $p^{\prime}$ then it can be shown that a firm will find it optimal not to increase price above $p^{\prime}-\varepsilon$, as long as $p^{\prime} \geq p^{*}+2 \varepsilon$ which implies that an upper bound on price is $p^{*}+\varepsilon$, which is the desired result.

Before executing that proof strategy, the following lemma will be needed. Recall that $\bar{\phi}\left(\mathbf{p}_{-i}\right)$ is the best reply correspondence for the following objective function:

$$
W\left(p_{i}, \mathbf{p}_{-i}\right) \equiv \pi\left(p_{i}, \mathbf{p}_{-i}\right)+\left(\frac{\delta}{1-\delta}\right) \pi\left(p_{i}, \ldots, p_{i}\right)
$$

Given its rivals price at $\mathbf{p}_{-i}$ in the current period, $W\left(p_{i}, \mathbf{p}_{-i}\right)$ is firm $i$ 's payoff from pricing at $p_{i}$ if it believed that all firms would match that price in all ensuing periods. Define $\bar{\phi}^{U}\left(\mathbf{p}_{-i}\right)$ to be the maximal element of $\bar{\phi}\left(\mathbf{p}_{-i}\right)$. Lemma 8 shows that the objective function is decreasing in $p_{i}$ for all $p_{i}>\bar{\phi}^{U}\left(\mathbf{p}_{-i}\right)$. The proof is in the Online Appendix.

Lemma 8 If $p^{\prime \prime}>p^{\prime} \geq \bar{\phi}^{U}\left(\mathbf{p}_{-i}\right)$ then

$$
\pi\left(p^{\prime}, \mathbf{p}_{-i}\right)+\left(\frac{\delta}{1-\delta}\right) \pi\left(p^{\prime}, \ldots, p^{\prime}\right)>\pi\left(p^{\prime \prime}, \mathbf{p}_{-i}\right)+\left(\frac{\delta}{1-\delta}\right) \pi\left(p^{\prime \prime}, \ldots, p^{\prime \prime}\right) .
$$

In that proof, it is shown:

$$
\text { if } \mathbf{p}_{-i} \leq\left(p^{\prime}, \ldots, p^{\prime}\right) \text { and } p^{\prime}>p^{*}+\varepsilon \text { then } \bar{\phi}^{U}\left(\mathbf{p}_{-i}\right) \leq p^{\prime}-\varepsilon \text {. }
$$

We are now ready to execute the proof strategy. As a preliminary step, note that if the period $t-1$ history is consistent with firms using PMP-compatible strategies and $\max \left\{p_{1}^{t-1}, \ldots, p_{n}^{t-1}\right\} \leq \widetilde{p}$ then a firm will not raise price above $\widetilde{p}$ because doing so 
would contradict it using a PMP-compatible strategy. Given it has PMP-consistent beliefs, Lemma 2 would then imply its strategy is not sequentially rational.

The first step is to show that level 1 of strong-delta-rationalizability (along with the first-order-belief considerations regarding PMP-consistent beliefs) implies that firms do not raise price to $\widetilde{p}$; that is, if the maximum price is below $\widetilde{p}$, it is not sequentially rational for a firm to raise price to $\widetilde{p}$ (or higher).

Consider a period $t-1$ history consistent with firms using PMP-compatible strategies and for which $\max \left\{p_{1}^{t-1}, \ldots, p_{n}^{t-1}\right\}<\widetilde{p}$. I want to show that a firm will not raise price to $\widetilde{p}$. If firm $i$ 's beliefs come from $\Delta^{P M P}$ then its beliefs on $\mathbf{p}_{-i}^{t}$ have support $\left\{\max \left\{p_{1}^{t-1}, \ldots, p_{n}^{t-1}\right\}, \ldots, \widetilde{p}\right\}^{n-1}$. For any $\mathbf{p}_{-i}^{t} \in\left\{\max \left\{p_{1}^{t-1}, \ldots, p_{n}^{t-1}\right\}, \ldots, \widetilde{p}\right\}^{n-1}$, Lemma 7 implies that a lower bound on its payoff from $p_{i}^{t}=\widetilde{p}-\varepsilon$ is

$$
\pi\left(\widetilde{p}-\varepsilon, \mathbf{p}_{-i}^{t}\right)+\left(\frac{\delta}{1-\delta}\right) \pi(\widetilde{p}-\varepsilon, \ldots, \widetilde{p}-\varepsilon) .
$$

For any prices for the other firms for period $t$ that are assigned positive probability $\mathbf{p}_{-i}^{t} \in\left\{\max \left\{p_{1}^{t-1}, \ldots, p_{n}^{t-1}\right\}, \ldots, \widetilde{p}\right\}^{n-1}-$ firm $i$ attributes a payoff from $p_{i}^{t}=\widetilde{p}$ equal to

$$
\pi\left(\widetilde{p}, \mathbf{p}_{-i}^{t}\right)+\left(\frac{\delta}{1-\delta}\right) \pi(\widetilde{p}, \ldots, \widetilde{p}) .
$$

Given that $\widetilde{p}>p^{*}+\varepsilon$ then $\bar{\phi}^{U}\left(\mathbf{p}_{-i}^{t}\right) \leq \widetilde{p}-\varepsilon$ for all $\mathbf{p}_{-i}^{t} \leq(\widetilde{p}, \ldots, \widetilde{p})$ by (14). It then follows from Lemma 8 that (15) strictly exceeds (16). Therefore, for any beliefs of firm $i$ with support $\left\{\max \left\{p_{1}^{t-1}, \ldots, p_{n}^{t-1}\right\}, \ldots, \widetilde{p}\right\}^{n-1}$, a price of $\widetilde{p}-\varepsilon$ is strictly preferred to $\widetilde{p}$, in which case firm $i$ pricing at $\widetilde{p}$ in period $t$ is not sequentially rational. Hence, $\Sigma_{i}\left(1, \Delta^{P M P}\right)$, and therefore $\Sigma_{i}\left(\infty, \Delta^{P M P}\right)$, excludes strategies that have firm $i$ raising price to $\widetilde{p}$; that is, it will not initiate a price increase that takes price to $\widetilde{p}$ (or higher) in period $t$ when $\max \left\{p_{1}^{t-1}, \ldots, p_{n}^{t-1}\right\}<\widetilde{p}$. In sum, if firm $i$ is sequentially rational and has PMP-consistent beliefs then it will not raise price beyond $\widetilde{p}-\varepsilon$.

As I just showed that $\Sigma_{-i}\left(1, \Delta^{P M P}\right)$ excludes strategies which have other firms raising price to $\widetilde{p}$ (or higher) when $\max \left\{p_{1}^{t-1}, \ldots, p_{n}^{t-1}\right\}<\widetilde{p}$, beliefs from

$$
\Phi^{i}\left(1, \Delta^{P M P}\right)=\left\{\mu^{i} \in \Delta^{P M P}: \forall h \in \mathcal{H}, S_{-i}(h) \cap \Sigma_{-i}\left(1, \Delta^{P M P}\right) \neq \varnothing \Rightarrow \mu^{i}\left(\Sigma_{-i}\left(1, \Delta^{P M P}\right) \mid h\right)=1\right\}
$$


put unit mass on strategies for the other firms which have them raise price no higher than $\widetilde{p}-\varepsilon$ (at least for histories consistent with $\left.\Sigma_{-i}\left(1, \Delta^{P M P}\right)\right)$. Let me next show that if $\mu^{i} \in \Phi^{i}\left(1, \Delta^{P M P}\right)$ then sequential rationality implies that firm $i$ will not lead price beyond $\tilde{p}-2 \varepsilon$; that is, $\Sigma_{i}\left(2, \Delta^{P M P}\right)=\rho_{i}\left(\Phi^{i}\left(1, \Delta^{P M P}\right)\right)$ excludes strategies that have firm $i$ raise price higher than $\widetilde{p}-2 \varepsilon$.

Consider a period $t-1$ history consistent with firms using strategies in $\Sigma_{-i}\left(1, \Delta^{P M P}\right)$ and for which $\max \left\{p_{1}^{t-1}, \ldots, p_{n}^{t-1}\right\}<\widetilde{p}-\varepsilon$. If $\mu^{i} \in \Phi^{i}\left(1, \Delta^{P M P}\right)$ then firm $i$ 's beliefs on $\mathbf{p}_{-i}^{t}$ have support $\left\{\max \left\{p_{1}^{t-1}, \ldots, p_{n}^{t-1}\right\}, \widetilde{p}-\varepsilon\right\}^{n-1}$. If $\widetilde{p}-\varepsilon>p^{*}+\varepsilon$ then, by (14), $\bar{\phi}^{U}\left(\mathbf{p}_{-i}^{t}\right) \leq \widetilde{p}-2 \varepsilon \forall \mathbf{p}_{-i}^{t} \leq(\widetilde{p}-\varepsilon, \ldots, \widetilde{p}-\varepsilon){ }^{32}$ By the same logic as above, a lower bound on firm $i$ 's payoff from $p_{i}^{t}=\widetilde{p}-2 \varepsilon$ is

$$
\pi\left(\widetilde{p}-2 \varepsilon, \mathbf{p}_{-i}^{t}\right)+\left(\frac{\delta}{1-\delta}\right) \pi(\widetilde{p}-2 \varepsilon, \ldots, \widetilde{p}-2 \varepsilon)
$$

while its payoff from $p_{i}^{t}=\widetilde{p}-\varepsilon$ is

$$
\pi\left(\widetilde{p}-\varepsilon, \mathbf{p}_{-i}^{t}\right)+\left(\frac{\delta}{1-\delta}\right) \pi(\widetilde{p}-\varepsilon, \ldots, \widetilde{p}-\varepsilon) .
$$

With (18), we used the fact that firm $i$ believes that other firms will not raise price above $\widetilde{p}-\varepsilon$. Again using Lemma 8, it is concluded that (17) strictly exceeds (18). Therefore, for any beliefs of firm $i$ over $\mathbf{p}_{-i}^{t}$ with support $\left\{\max \left\{p_{1}^{t-1}, \ldots, p_{n}^{t-1}\right\}, \ldots, \widetilde{p}-\varepsilon\right\}^{n-1}$, a price of $\widetilde{p}-2 \varepsilon$ is strictly preferred to $\widetilde{p}-\varepsilon$. Hence, $\Sigma_{i}\left(2, \Delta^{P M P}\right)$, and therefore $\Sigma_{i}\left(\infty, \Delta^{P M P}\right)$, excludes strategies which have firm $i$ raising price to $\widetilde{p}-\varepsilon$; that is, it will not price at $\widetilde{p}-\varepsilon$ (or higher) in period $t$ when $\max \left\{p_{1}^{t-1}, \ldots, p_{n}^{t-1}\right\}<\widetilde{p}-\varepsilon$. In sum, if firm $i$ is sequentially rational and has beliefs that other firms use strategies which are sequentially rational for PMP-consistent beliefs then it will not initiate a price increase that takes price above $\widetilde{p}-2 \varepsilon$. Hence, all firms will not raise price above $\widetilde{p}-2 \varepsilon$.

The proof is completed by induction. Consider a period $t-1$ history consistent with firms using strategies in $\Sigma_{-i}\left(k, \Delta^{P M P}\right)$ and for which $\max \left\{p_{1}^{t-1}, \ldots, p_{n}^{t-1}\right\}<$

\footnotetext{
${ }^{32}$ If instead $\widetilde{p}-\varepsilon \leq p^{*}+\varepsilon$ then, given that it has already been shown $\widetilde{p}-\varepsilon$ is an upper bound on the limit price, it follows that $p^{*}+\varepsilon$ is an upper bound and we're done.
} 
$\widetilde{p}-k \varepsilon$ where $k \in\{1,2, \ldots\}$, and $\widetilde{p}-k \varepsilon>p^{*}+\varepsilon$. As the presumption in the inductive step, suppose that $\mu^{i} \in \Phi^{i}\left(k, \Delta^{P M P}\right)$ implies firm $i$ 's beliefs on $\mathbf{p}_{-i}^{t}$ have support $\left\{\max \left\{p_{1}^{t-1}, \ldots, p_{n}^{t-1}\right\}, \widetilde{p}-k \varepsilon\right\}^{n-1}$. If $\widetilde{p}-k \varepsilon>p^{*}+\varepsilon$ then, by $(14), \bar{\phi}^{U}\left(\mathbf{p}_{-i}^{t}\right) \leq$ $\widetilde{p}-(k+1) \varepsilon \forall \mathbf{p}_{-i}^{t} \leq(\widetilde{p}-k \varepsilon, \ldots, \widetilde{p}-k \varepsilon)$. By the same logic as above, a lower bound on firm $i$ 's payoff from $p_{i}^{t}=\widetilde{p}-(k+1) \varepsilon$ is

$$
\pi\left(\widetilde{p}-(k+1) \varepsilon, \mathbf{p}_{-i}^{t}\right)+\left(\frac{\delta}{1-\delta}\right) \pi(\widetilde{p}-(k+1) \varepsilon, \ldots, \widetilde{p}-(k+1) \varepsilon),
$$

while its payoff from $p_{i}^{t}=\widetilde{p}-k \varepsilon$ is

$$
\pi\left(\widetilde{p}-k \varepsilon, \mathbf{p}_{-i}^{t}\right)+\left(\frac{\delta}{1-\delta}\right) \pi(\widetilde{p}-k \varepsilon, \ldots, \widetilde{p}-k \varepsilon) .
$$

With (20), we used the fact that firm $i$ believes that other firms will not raise price above $\widetilde{p}-k \varepsilon$. Again using Lemma 8, it is concluded that (19) strictly exceeds (20). Therefore, for any beliefs of firm $i$ over $\mathbf{p}_{-i}^{t}$ with support $\left\{\max \left\{p_{1}^{t-1}, \ldots, p_{n}^{t-1}\right\}, \ldots, \widetilde{p}-k \varepsilon\right\}^{n-1}$, a price of $\widetilde{p}-(k+1) \varepsilon$ is strictly preferred to $\widetilde{p}-k \varepsilon$. Hence, $\Sigma_{i}\left(k+1, \Delta^{P M P}\right)$, and therefore $\Sigma_{i}\left(\infty, \Delta^{P M P}\right)$, excludes strategies which have firm $i$ raising price to $\widetilde{p}-k \varepsilon$; that is, it will not price at $\widetilde{p}-k \varepsilon$ (or higher) in period $t$ when $\max \left\{p_{1}^{t-1}, \ldots, p_{n}^{t-1}\right\}<$ $\widetilde{p}-k \varepsilon$. Hence, all firms will not raise price above $\widetilde{p}-(k+1) \varepsilon$. This argument works as long as $\widetilde{p}-k \varepsilon>p^{*}+\varepsilon$. I conclude that if the strategy profile is in $\prod_{i=1}^{n} \Sigma_{i}\left(\infty, \Delta^{P M P}\right)$ then price is bounded above by $p^{*}+\varepsilon$.

Proof of Theorem 5: $p^{*}$ is defined by

$$
\frac{\partial W\left(p^{*}, \ldots, p^{*}\right)}{\partial p_{i}}=\frac{\partial \pi\left(p^{*}, \ldots, p^{*}\right)}{\partial p_{i}}+\delta \sum_{j \neq i}^{n} \frac{\partial \pi\left(p^{*}, \ldots, p^{*}\right)}{\partial p_{j}}=0 .
$$

For all $p \geq p^{M}$,

$$
\frac{\partial \pi(p, \ldots, p)}{\partial p_{i}}<0 \text { and } \sum_{j=1}^{n} \frac{\partial \pi(p, \ldots, p)}{\partial p_{j}} \leq 0,
$$

which implies $p^{*}<p^{M}$ by the strict concavity of $W$ in own price. To show $p^{*}>p^{N}$, note that $\phi(p, \ldots, p)>\psi(p, \ldots, p)$ and $\psi(p, \ldots, p) \geq p \forall p \leq p^{N}$ implies $\phi(p, \ldots, p)>p$ $\forall p \leq p^{N}$. Since $\phi(p, \ldots, p) \gtreqless p$ as $p \lesseqgtr p^{*}$ then $p^{*}>p^{N}$. We have then shown $p^{*} \in\left(p^{N}, p^{M}\right)$. 
If $\widetilde{p}=p^{M}$ then $p^{*} \in\left(p^{N}, \widetilde{p}\right)$ and we are done. From hereon, suppose $\widetilde{p}<p^{M}$ in which case the incentive compatibility constraint (ICC) binds:

$$
\frac{\pi(\widetilde{p}, \ldots, \widetilde{p})}{1-\delta}=\pi(\psi(\widetilde{p}, \ldots, \widetilde{p}), \widetilde{p}, \ldots, \widetilde{p})+\left(\frac{\delta}{1-\delta}\right) \pi\left(p^{N}, \ldots, p^{N}\right)
$$

As $p \in\left(p^{N}, p^{*}\right]$ implies $\psi(p, \ldots, p)<p \leq \phi(p, \ldots, p)$ then, by the strict concavity of $W, W(p, \ldots, p)>W(\psi(p), p, \ldots, p)$, which is equivalently expressed as

$$
\frac{\pi(p, \ldots, p)}{1-\delta}>\pi(\psi(p), p, \ldots, p)+\left(\frac{\delta}{1-\delta}\right) \pi(\psi(p), \ldots, \psi(p)) .
$$

$p>p^{N}$ implies $\psi(p, \ldots, p) \in\left(p^{N}, p\right)$. Next note $\psi(p, \ldots, p)<p \leq p^{*}<p^{M}$ implies $\psi(p, \ldots, p)<p^{M}$. It then follows from $\psi(p, \ldots, p) \in\left(p^{N}, p^{M}\right)$ that $\pi(\psi(p), \ldots, \psi(p))>$ $\pi\left(p^{N}, \ldots, p^{N}\right)$. Using this property in $(22)$, we have

$$
\frac{\pi(p, \ldots, p)}{1-\delta}>\pi(\psi(p), p, \ldots, p)+\left(\frac{\delta}{1-\delta}\right) \pi\left(p^{N}, \ldots, p^{N}\right), \forall p \in\left(p^{N}, p^{*}\right] .
$$

Therefore, $p \in\left(p^{N}, p^{*}\right]$ is sustainable with the grim trigger strategy. Given (21) where the ICC binds for $p=\widetilde{p}$ - and evaluating (23) at $p=p^{*}$ - so the ICC does not bind - it follows from $(2)$ that $\widetilde{p}>p^{*}$.

Proof of Theorem 6: If $s$ is a strategy profile and $Q$ is a collection of infinite price paths for the game then define $\mu_{s}(Q)$ to be the probability measure on $Q$ induced by $s$. By A1-A2, a strategy profile is an element of $\prod_{i=1}^{n} \Sigma_{i}\left(\infty, \Delta^{P M P}\right)$ and, by Theorem 4 , the price path converges in finite time.

Suppose, contrary to the statement of Theorem 6, the strategy profile, denoted $\widetilde{s}$, has price converge to $p^{\prime}<p^{*}-\varepsilon$. It is then the case that there exists $T^{\prime}$ such that $\mu_{\widehat{s}}\left(Q_{\widehat{p}}\right)=1$ for all infinite price paths $Q_{\widehat{p}}$ with the property: $p_{1}^{t}=\cdots=p_{n}^{t}=p^{\prime}$ $\forall t \geq T^{\prime}$. By Theorem 1 of Kalai and Lehrer (1993), $\exists T(\eta)$ such that firm $i$ 's beliefs on the infinite price paths, denoted $\mu^{i}$, have the property that $\mu_{\widetilde{s}}$ is $\eta$-close to $\mu^{i}$ for price paths starting at $t, \forall t \geq T(\eta) .{ }^{33}$ Given that $\mu_{\widetilde{s}}\left(Q_{\widehat{p}}\right)=1 \forall t \geq \max \left\{T^{\prime}, T(\eta)\right\}$

\footnotetext{
${ }^{33}$ Definition 1 (Kalai and Lehrer, 1993): Let $\eta>0$ and let $\mu$ and $\widetilde{\mu}$ be two probability measures defined on the same space. $\mu$ is said to be $\eta$-close to $\widetilde{\mu}$ if there is a measurable set $Q$ satisfying: (i) $\mu(Q)$ and $\widetilde{\mu}(Q)$ are greater than $1-\eta$; and (ii) for every measurable set $X \subseteq Q$ : $(1-\eta) \widetilde{\mu}(X) \leq$ $\mu(X) \leq(1+\eta) \widetilde{\mu}(X)$.
} 
then $\mu^{i}$ must assign probability of at least $1-\eta$ to the future price path having the property: $p_{1}^{t}=\cdots=p_{n}^{t}=p^{\prime} \forall t \geq \max \left\{T^{\prime}, T(\eta)\right\} .^{34}$

Given these beliefs, let us evaluate sequentially rational play for firm $i$. For $t \geq$ $\max \left\{T^{\prime}, T(\eta)\right\}$, firm $i$ 's expected payoff from acting according to its strategy and pricing at $p^{\prime}$ has an upper bound of

$$
(1-\eta)\left(\frac{\pi\left(p^{\prime}, \ldots, p^{\prime}\right)}{1-\delta}\right)+\eta\left(\frac{1}{1-\delta}\right) \bar{\pi}
$$

Probability $1-\eta$ is assigned to the "true" future price path in which price is always $p^{\prime}$, and the remaining probability is assigned to a price path yielding $\bar{\pi}$ which is the maximal profit that a firm can earn (in order to provide an upper bound on the payoff). Now consider firm $i$ deviating from its strategy of pricing at $p^{\prime}$ by pricing instead at $\phi\left(p^{\prime}, \ldots, p^{\prime}\right)\left(>p^{\prime}\right)$. Firm $i$ 's expected payoff has a lower bound of

$$
(1-\eta)\left[\pi\left(\phi\left(p^{\prime}, \ldots, p^{\prime}\right), p^{\prime}, \ldots, p^{\prime}\right)+\left(\frac{\delta}{1-\delta}\right) \pi\left(\phi\left(p^{\prime}, \ldots, p^{\prime}\right), \ldots, \phi\left(p^{\prime}, \ldots, p^{\prime}\right)\right)\right] .
$$

Probability $1-\eta$ is assigned to other firms pricing at $p^{\prime}$ in the current period and only matching firm $i$ 's price of $\phi\left(p^{\prime}, \ldots, p^{\prime}\right)$ thereafter, which is the worst case scenario given firm $i$ has PMP-consistent beliefs. A zero payoff is assigned to the remaining probability $\eta$ to give us a lower bound. We want to show that pricing at $p^{\prime}$ is not optimal - and thus inconsistent with sequential rationality - which is the case if (25) exceeds (24):

$$
\begin{aligned}
& (1-\eta)\left[\pi\left(\phi\left(p^{\prime}, \ldots, p^{\prime}\right), p^{\prime}, \ldots, p^{\prime}\right)+\left(\frac{\delta}{1-\delta}\right) \pi\left(\phi\left(p^{\prime}, \ldots, p^{\prime}\right), \ldots, \phi\left(p^{\prime}, \ldots, p^{\prime}\right)\right)\right] \\
> & (1-\eta)\left(\frac{\pi\left(p^{\prime}, \ldots, p^{\prime}\right)}{1-\delta}\right)+\eta\left(\frac{1}{1-\delta}\right) \bar{\pi}
\end{aligned}
$$

\footnotetext{
${ }^{34} \mathrm{I}$ am only using property (i) in Definition 1 of Kalai and Lehrer (1993).
} 


$$
\begin{aligned}
& (1-\eta)\left[\pi\left(\phi\left(p^{\prime}, \ldots, p^{\prime}\right), p^{\prime}, \ldots, p^{\prime}\right)+\left(\frac{\delta}{1-\delta}\right) \pi\left(\phi\left(p^{\prime}, \ldots, p^{\prime}\right), \ldots, \phi\left(p^{\prime}, \ldots, p^{\prime}\right)\right)-\frac{\pi\left(p^{\prime}, \ldots, p^{\prime}\right)}{1-\delta}\right] \\
> & \eta\left(\frac{1}{1-\delta}\right) \bar{\pi} .
\end{aligned}
$$

Given that $p^{\prime}<p^{*}-\varepsilon$ then the first bracketed term in (26) is strictly positive. Hence, for $\eta$ sufficiently small, (26) holds. Thus, if $t$ is sufficiently great, firm $i$ 's beliefs are such that pricing at $p^{\prime}$ in period $t$ is non-optimal. Therefore, I conclude that price cannot converge to a value below $p^{*}-\varepsilon$. Given that Theorem 4 showed that an upper bound on convergence is $p^{*}+\varepsilon$, it is concluded that prices converges to some value in $\left\{p^{*}-\varepsilon, p^{*}, p^{*}+\varepsilon\right\}$.

\section{Appendix B}

By Sea Moon (Simon) Cho <seamcho@sas.upenn.edu>

Department of Mathematics, University of Pennsylvania

To prove that $\cup_{s \in \Pi_{j=1}^{n}} \Sigma_{j}\left(\infty, \Delta^{P M P}\right) \omega(s)$ is countable, it is sufficient to show that $\cup_{s \in\left(S^{P M P}\right)^{n}} \omega(s)$ is countable because $\Pi_{j=1}^{n} \Sigma_{j}\left(\infty, \Delta^{P M P}\right) \subset\left(S^{P M P}\right)^{n}$. Recall that $\Omega$ is a finite set of real numbers. Fix two numbers $p^{\prime}, p^{\prime \prime} \in \Omega$, where $p^{\prime}<p^{\prime \prime}$. Consider the following class of sequences $\left\{p_{i}^{t}\right\}$ of numbers from $\Omega$ indexed by $t$ and generated by the following inductive procedure. $p_{i}^{0}$ and $p_{i}^{1}$ are arbitrary. For $t \geq 2$, we let the possibilities for $p_{i}^{t}$ be as follows:

- Case (1): If it is not true that $p_{j}^{\tau} \geq \min \left\{\max \left\{p_{1}^{\tau-1}, \ldots, p_{n}^{\tau-1}\right\}, p^{\prime \prime}\right\} \forall j$ and $\forall \tau \leq t-1$, then $p_{i}^{t}=p^{\prime}$.

- Case (2): If $p_{j}^{\tau} \geq \min \left\{\max \left\{p_{1}^{\tau-1}, \ldots, p_{n}^{\tau-1}\right\}, p^{\prime \prime}\right\} \forall j$ and $\forall \tau \leq t-1$, and if also $\max \left\{p_{1}^{t-1}, \ldots, p_{n}^{t-1}\right\} \geq p^{\prime \prime}$, then $p_{i}^{t}=p^{\prime \prime}$. 
- Case (3): If $p_{j}^{\tau} \geq \min \left\{\max \left\{p_{1}^{\tau-1}, \ldots, p_{n}^{\tau-1}\right\}, p^{\prime \prime}\right\} \forall j$ and $\forall \tau \leq t-1$, and if also $\max \left\{p_{1}^{t-1}, \ldots, p_{n}^{t-1}\right\}<p^{\prime \prime}$, then $p_{i}^{t}$ is some number such that $\max \left\{p_{1}^{t-1}, \ldots, p_{n}^{t-1}\right\} \leq$ $p_{i}^{t} \leq p^{\prime \prime}$.

In order to prove that the set of possible sequences $\left\{p_{i}^{t}\right\}$ given by the above description is countable, let me first show any sequence $\left\{p_{i}^{t}\right\}$ must be eventually constant. This mean that, for any such sequence, one can find some $T$ such that $\left\{p_{i}^{t}\right\}$ is the same for all $t \geq T$. First note that cases (1), (2), and (3) account for all possible situations. Further note that if case (1) holds at some $t=T$, then case (1) must hold for all $t \geq T$, by precisely the same conditions that made case (1) hold at $t=T$, so if case (1) ever holds then the sequence is eventually constant. If case (2) holds at some $t=T$, then either case (1) or case (2) - but not case (3) - could hold at $t=T+1$. Thus if case (2) holds at some time $t=T$, then case (3) can never hold afterwards, and so either case (2) holds for all $t \geq T$, or case (1) holds at some $t=T^{\prime}>T$, after which case (1) must hold forever. Therefore, if case (2) ever holds,

then the sequence must become eventually constant. Thus, if a sequence $\left\{p_{i}^{t}\right\}$ is not eventually constant then case (3) must hold for all $t \in \mathbb{N}$. But this implies that $\left\{p_{i}^{t}\right\}$ is a weakly increasing sequence which is bounded above by $p^{\prime \prime}$. It is clear that such a sequence must in fact be eventually constant, since there are only a finite number of elements in $\Omega$ below $p^{\prime \prime}$.

The argument is concluded by noting that the set of sequences of numbers from a finite set which are eventually constant is countably infinite.

\section{References}

[1] Andreoli-Versbach, Patrick and Jens-Uwe Franck, "Endogenous Price Commitment, Sticky and Leadership Pricing: Evidence from the Italian Petrol Market," International Journal of Industrial Organization, 40 (2015), 32-48. 
[2] Aoyagi, Masaki, "Collusion in Dynamic Bertrand Oligopoly with Correlated Private Signals and Communication," Journal of Economic Theory, 102 (2002), 229-248.

[3] Athey, Susan and Kyle Bagwell, "Optimal Collusion with Private Information," RAND Journal of Economics, 32 (2001), 428-465.

[4] Athey, Susan and Kyle Bagwell, "Collusion with Persistent Cost Shocks," Econometrica, 76 (2008), 493-540.

[5] Awaya, Yu and Vijay Krishna, "On Communication and Collusion," American Economic Review, 106 (2016), 285-315.

[6] Battigalli, Pierpaolo, "Rationalizability in Infinite, Dynamic Games of Incomplete Information," Research in Economics, 37 (2003), 1-38.

[7] Battigalli, Pierpaolo and Andrea Prestipino, "Transparent Restrictions on Beliefs and Forward-Induction Reasoning in Games with Asymmetric Information," B.E. Journal of Theoretical Economics, 13 (2013), 79-130.

[8] Battigalli, Pierpaolo and Marciano Siniscalchi, "Rationalization and Incomplete Information," Advances in Theoretical Economics, 3 (2003) (1), Article 3.

[9] Borenstein, Severin, "Rapid Price Communication and Coordination: The Airline Tariff Publishing Case (1994)," in The Antitrust Revolution, 4th edition, John E. Kwoka, Jr. and Lawrence J. White, eds., New York: Oxford University Press, 2004.

[10] Catonini, Emiliano, "Non-binding Agreements and Forward Induction Reasoning," Higher School of Economics, April 2015a.

[11] Catonini, Emiliano, "Selecting Strongly Rationalizable Strategies," Higher School of Economics, June 2015b. 
[12] Chamberlain, Edward, The Theory of Monopolistic Competition, Cambridge: Harvard University Press, 1938.

[13] Chan, Jimmy and Wenzhang Zhang, "Collusion Enforcement with Private Information and Private Monitoring," Journal of Economic Theory, 157 (2015), $188-211$.

[14] Clark, Robert and Jean-François Houde, "Collusion with Asymmetric Retailers: Evidence from a Gasoline Price-Fixing Case," HEC Montréal, February 2011.

[15] Cramton, Peter and Jesse A. Schwartz, "Collusive Bidding: Lessons from the FCC Spectrum Auctions," Journal of Regulatory Economics, 17 (2000), 229-252.

[16] Garrod, Luke, "Collusive Price Rigidity under Price-Matching Punishments," International Journal of Industrial Organization, 30 (2012), 471-482.

[17] Gerlach, Heiko, "Stochastic Market Sharing, Partial Communication and Collusion," International Journal of Industrial Organization, 27 (2009), 655-666.

[18] Hanazono, Makato and Huanxing Yang, "Collusion, Fluctuating Demand, and Price Rigidity," International Economic Review, 48 (2007), 483-515.

[19] Harrington, Joseph E. Jr., "How Do Cartels Operate?," Foundations and Trends in Microeconomics, Vol. 2, Issue 1, July 2006.

[20] Harrington, Joseph E. Jr., "Posted Pricing as a Plus Factor," Journal of Competition Law and Economics, 7 (2011), 1-35.

[21] Harrington, Joseph E. Jr. and Andrzej Skrzypacz, "Private Monitoring and Communication in Cartels: Explaining Recent Collusive Practices," American Economic Review, 101 (2011), 2425-2449.

[22] Harrington, Joseph E. Jr. and Wei Zhao, "Signaling and Tacit Collusion in an Infinitely Repeated Prisoners' Dilemma," Mathematical Social Sciences, 64 (2012), 277-289. 
[23] Kalai, Ehud and Ehud Lehrer, "Rational Learning Leads to Nash Equilibrium," Econometrica, 561 (1993), 1019-1045.

[24] Kaplow, Louis, Competition Policy and Price Fixing, Princeton, N.J.: Princeton University Press, 2013.

[25] Lewis, Michael S., "Price Leadership and Coordination in Retail Gasoline Markets with Price Cycles," International Journal of Industrial Organization, 30 (2012), 342-351.

[26] Lockwood, Ben and Jonathan P. Thomas, "Gradualism and Irreversibility," Review of Economic Studies, 69 (2002), 339-356.

[27] Lu, Yuanzhu and Julian Wright, "Tacit Collusion with Price-Matching Punishments," International Journal of Industrial Organization, 28 (2010), 298-306.

[28] Markham, Jesse W., "The Nature and Significance of Price Leadership," American Economic Review, 41 (1951), 891-905.

[29] Marshall, Robert C. and Leslie M. Marx, The Economics of Collusion: Cartels and Bidding Rings, Cambridge, Mass.: The MIT Press, 2012.

[30] Mouraviev, Igor and Patrick Rey, "Collusion and Leadership," International Journal of Industrial Organization, 29 (2011), 705-717.

[31] Pastine, Ivan and Tuvana Pastine, "Cost of Delay and Endogenous Price Leadership," International Journal of Industrial Organization, 22 (2004), 135-145.

[32] Rotemberg, Julio J. and Garth Saloner, "Price Leadership," Journal of Industrial Economics, 39 (1990), 93-111.

[33] Scherer, F. M., Industrial Market Structure and Economic Performance, 2nd Edition, Boston: Houghton Mifflin, 1980. 
[34] Seaton, Jonathan S. and Michael Waterson, "Identifying and Characterising Price Leadership in British Supermarkets," International Journal of Industrial Organization, 31 (2013), 392-403.

[35] Spector, David, "Facilitating Collusion by Exchanging Non-verifiable Sales Reports," Paris School of Economics, February 2015.

[36] Wang, Zhongmin, "(Mixed) Strategy in Oligopoly Pricing: Evidence from Gasoline Pricing Cycles Before and Under a Timing Regulation," Journal of Political Economy, 117 (2009), 987-1030. 